\title{
A model for hydrogen sulfide poisoning in proton exchange membrane fuel cells
}

\author{
A.A. Shah*, F.C. Walsh \\ Energy Technology Research Group, School of Engineering Sciences, University of Southampton, University Road, Highfields, Southampton SO17 1BJ, United Kingdom
}

\section{A R T I C L E I N F O}

\section{Article history:}

Received 19 February 2008

Received in revised form 22 May 2008

Accepted 28 June 2008

Available online 10 July 2008

\section{Keywords:}

Degradation

Hydrogen sulfide poisoning

Mathematical model

PEM fuel cell

Simulation

\begin{abstract}
A B S T R A C T
A polymer-electrolyte fuel cell model that incorporates the effects of hydrogen sulfide contaminant on performance is developed. The model is transient, fully two-phase and non-isothermal and includes a complex kinetic mechanism to describe the electrode reactions. Comparisons between the simulation results and data in the literature demonstrate that known trends are well captured. The effects of temperature and relative humidity variations in the anode stream are investigated, with further comparisons to experimental data and a proposed explanation for the nonlinear behaviour observed in the experiments of Mohtadi et al. [R. Mohatadi, W.-K. Lee, J. van Zee, Appl. Catal. B 56 (2005) 37-42)]. Extensions to the model and future work are discussed.
\end{abstract}

(c) 2008 Elsevier B.V. All rights reserved.

\section{Introduction}

The proton exchange membrane (PEM) fuel cell has significant potential as an efficient and environmentally friendly power source. The main electrochemical reactions involve hydrogen and oxygen and in the absence of additional "side" reactions the net product is simply water. However, the main intended sources of hydrogen $\left(\mathrm{H}_{2}\right)$ are reformed hydrocarbons [2], which contain traces of ammonia, hydrogen sulfide and carbon monoxide. Each of these compounds engender reactions that seriously degrade performance and can potentially cause long-term harm to the positive electrode [3-5].

Carbon-monoxide ( $\mathrm{CO}$ ) poisoning has been studied quite extensively and the highly detrimental effects of small traces of $\mathrm{CO}$ in the anode fuel stream are well-documented $[3,6,7]$. Several mitigation techniques have been proposed and analysed, notably oxygen bleeding and the use of alternative catalysts such as platinumruthenium. The influence of hydrogen sulfide $\left(\mathrm{H}_{2} \mathrm{~S}\right)$, although first studied as early as 1971 by Loučka [4], is less well characterised. Several researchers have shown that small traces of $\mathrm{H}_{2} \mathrm{~S}$ severely affect performance, on a scale at least comparable with CO [1,4,8-18]. However, few mitigation strategies have been proposed and it has been reported that platinum-ruthenium, while effective against $\mathrm{CO}$, is not $\mathrm{H}_{2} \mathrm{~S}$ tolerant $[13,15]$. There is a clear need, therefore, for a better fundamental understanding and characterisation of the $\mathrm{H}_{2} \mathrm{~S}$ poisoning process.

\footnotetext{
* Corresponding author. Tel.: +44 238059 8520; fax: +44 2380593131.

E-mail address: A.Shah@soton.ac.uk (A.A. Shah).
}

Modelling and simulation are well-established tools in PEM fuel cell research, particularly with a focus on the effects of water retention in the cathode at steady state. The methodologies and techniques were recently reviewed in $[19,20]$. Examples of timedependent models can be found in [21-23] and, in contrast to steady-state models, are relatively few in number, even though in potential dynamic applications such as automobile power, cell stacks rarely operate at steady state. Degradation mechanisms, moreover, are inherently transient, impacting performance on a long time scale, as in the case of carbon corrosion, or on a relatively short time scale, as with $\mathrm{H}_{2} \mathrm{~S}$ poisoning. Models of such mechanisms, to which one can add radical attack of the membrane and platinum dissolution and sintering, are rare. This is somewhat surprising considering that the commercial viability of PEM fuel cells is largely dependent upon overcoming or minimising degradation phenomena, many of which can potentially be simulated on a computer in a fraction of the time required for long-life experiments.

It is also important to note that degradation is typically influenced strongly by the properties of the cell components, by heat and mass transport, and by the operating conditions-this is certainly true of $\mathrm{CO}$ poisoning and membrane failure. In order to keep fitting parameters to a minimum and simulate operation over a broad range of conditions a model should ideally include these features explicitly. An earlier paper laid the foundations for a transient model of $\mathrm{CO}$ poisoning and oxygen bleeding on both platinum and platinum-ruthenium that explicitly incorporated the entire MEA, two-phase flow and temperature variations [24]. In this paper a similarly detailed model is developed to study the $\mathrm{H}_{2} \mathrm{~S}$ poisoning mechanism, using the results in $[1,4,8-18]$ to derive a detailed sub-model for the anode kinetics. 


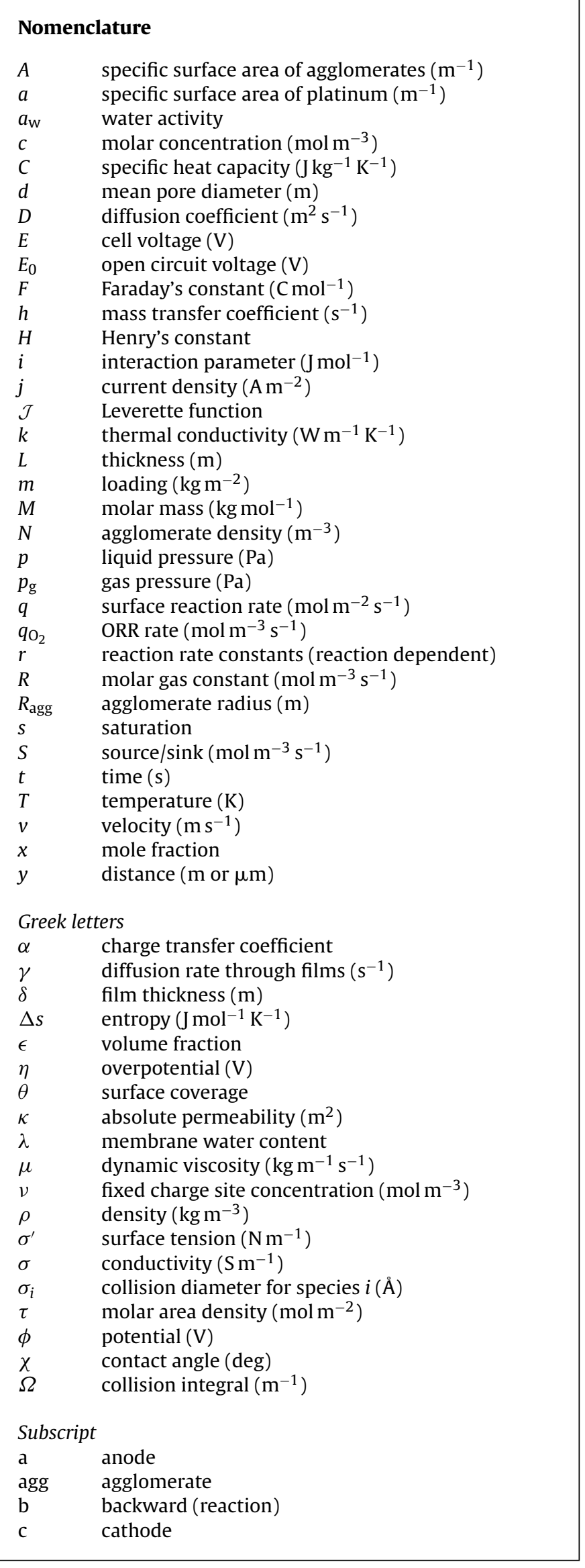

\begin{tabular}{|ll|}
\hline C & catalyst layer \\
cap & capillary \\
d & dissolved \\
e & electrolyte \\
g & gas \\
G & gas diffusion layer \\
$f$ & forward (rate constants) \\
v & vapour \\
l & liquid \\
$p$ & pore space \\
pt & platinum \\
ref & reference \\
S & solid/electronic \\
O & reference \\
v $\leftrightarrow 1$ & vapour to liquid \\
v $\leftrightarrow$ d & vapour to dissolved \\
d $\leftrightarrow$ l & dissolved to liquid \\
Superscript \\
l & equilibrium between liquid and dissolved phases \\
$*$ & equilibrium between vapour and dissolved phases \\
- & boundary/initial value \\
A & volume average \\
& \\
\hline
\end{tabular}

The next section describes the conservation equations and kinetic model. In Section 3 simulation results are presented, with a comparison to experimental data available in the literature. The effects of channel temperature and water activity variations on the poisoning process are then investigated, with further comparisons to experimental data from Mohtadi et al. [1]. A summary of the results and a discussion of future work are given in Section 4.

\section{Model}

In this section the main features of the model and the underlying assumptions are enumerated, followed by a description of the conservation principles, the kinetic model, the initial and boundary conditions and the numerical implementation. Details of the parameters and the fitting procedure are also provided.

1. Domain. The domain includes the entire MEA as depicted in Fig. 1. Each component is modelled explicitly. Where convenient the following notation is used: GDL for the Gas Diffusion Layer, CCL for the Cathode Catalyst Layer and ACL for the Anode Catalyst Layer.

2. Catalyst layers. The so-called "agglomerates model" is employed, in which the carbon support is assumed to form spherical clusters, surrounded by layers of electrolyte and liquid water. The pores between agglomerates are referred to as primary pores, distinct from the smaller pores between the carbon particles. Sufficient contact between the agglomerates to permit electron and proton migration is assumed.

3. Reactant transport and transfer. The reactants are considered to exist as species in both the gas and electrolyte phases. Deviations from Henry's law provide a driving force for interfacial mass transfer. Water exists in three forms: dissolved, vapour and liquid. Mass transfer is driven by deviations from an appropriate equilibrium.

4. Water. Water is considered to exist in three forms: as a dissolved species, as vapour and as liquid. It assumed that the net water produced is in liquid form. Condensation and evaporation are modelled using the approach in [25-27], and references therein, 


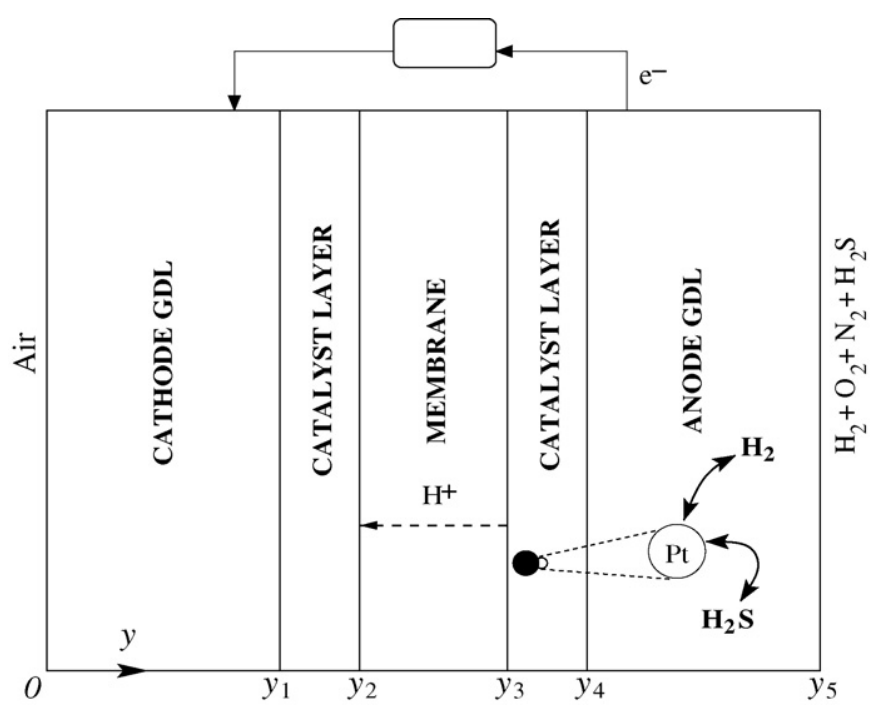

Fig. 1. A schematic of the one-dimensional domain considered in the model.

dictated by the deviation of the local thermodynamic state from equilibrium. In a similar fashion, phase change between vapour and dissolved water and between liquid and dissolved water are introduced by considering deviations from appropriate equlibrium states.

5. Charge. For the conservation of charge, electroneutrality and a pseudo steady-state apply. The justification can be found in [28].

6. Kinetics. The kinetics of oxygen reduction are assumed to follow a global mechanism, as is usually the case in modelling studies. The kinetic model at the anode is derived from the experimental results in $[1,10-12,14]$.

\subsection{Conservation principles}

\subsubsection{Reactant mass conservation}

Let $s$ denote liquid-water saturation, and $c_{i}$ and $c_{\mathrm{H}_{2} \mathrm{O}}^{v}$ the pore concentrations of species $i=\mathrm{O}_{2}, \mathrm{H}_{2}, \mathrm{~N}_{2}, \mathrm{H}_{2} \mathrm{~S}, \mathrm{SO}_{3}$ and vapour, respectively. The concentration of species $i$ dissolved in the electrolyte and membrane is denoted $c_{i}^{d}$. Mass balance equations in gas phase are derived by taking into account transport by diffusion and convection, and mass transfer to and from the electrolyte:

$\frac{\partial}{\partial t}\left(\epsilon(1-s) c_{i}\right)-\frac{\partial}{\partial y}\left(D_{i} \frac{\partial c_{i}}{\partial y}-v_{\mathrm{g}} c_{i}\right)=-S_{p i}$

$\frac{\partial}{\partial t}\left(\epsilon(1-s) c_{\mathrm{H}_{2} \mathrm{O}}^{v}\right)-\frac{\partial}{\partial y}\left(D_{\mathrm{H}_{2} \mathrm{O}}^{v} \frac{\partial c_{\mathrm{H}_{2} \mathrm{O}}^{v}}{\partial y}-v_{\mathrm{g}} c_{\mathrm{H}_{2} \mathrm{O}}^{v}\right)=S_{\mathrm{V} \leftrightarrow 1}+\nu S_{\mathrm{V} \leftrightarrow \mathrm{d}}$

where $D_{i}$ is the free-space diffusion coefficient of species $i$ in the pore space and $D_{\mathrm{H}_{2} \mathrm{O}}^{v}$ is the free-space diffusion coefficient for water vapour; $T$ is temperature and $p_{\mathrm{g}}$ is the gas pressure; $\epsilon$ is the porosity, which takes the value $\epsilon=\epsilon_{p}$ in the catalyst layers and $\epsilon=\epsilon_{\mathrm{G}}$ in the gas diffusion layers. The Chapman-Enskog approximation [29], and Bruggemann corrections have been used for the diffusion coefficients, with values referred to nitrogen:

$D_{i}=0.01858[\epsilon(1-s)]^{3 / 2} \frac{T^{3 / 2}}{p_{\mathrm{g}}} \frac{\sqrt{\left(1 / M_{i}\right)+\left(1 / M_{\mathrm{N}_{2}}\right)}}{\sigma_{i \mathrm{~N}_{2}}^{2} \Omega_{i_{2}}}$

in $\mathrm{m}^{2} \mathrm{~s}^{-1}$. For each species $i=M_{i}$ is the molar mass, $\sigma_{i \mathrm{~N}_{2}}$ is the mean collision diameter (Lennard-Jones force constant) and $\Omega_{i \mathrm{~N}_{2}}$ is the collision integral. The vapour diffusion coefficient, $D_{\mathrm{H}_{2} \mathrm{O}}^{v}$, can
Table 1

Sources and sinks for the gas phase Eqs. (1)-(2)

\begin{tabular}{|c|c|c|c|}
\hline Term & $\mathrm{ACL}$ & $\mathrm{CCL}$ & GDL \\
\hline$S_{p i}$ & $h_{\mathrm{pe}, i}\left(H_{i} c_{i}-c_{i}^{d}\right)$ & $h_{\mathrm{pe}, i}\left(H_{i} c_{i}-c_{i}^{d}\right)$ & 0 \\
\hline$S_{\mathrm{V} \leftrightarrow 1}$ & $-h_{v \leftrightarrow l}\left(x_{v} p_{\mathrm{g}}-p_{\text {sat }}\right)$ & $-h_{\mathrm{v} \leftrightarrow 1}\left(x_{v} p_{\mathrm{g}}-p_{\mathrm{sat}}\right)$ & $-h_{\mathrm{v} \leftrightarrow 1}\left(x_{v} p_{\mathrm{g}}-p_{\mathrm{sat}}\right)$ \\
\hline$S_{\mathrm{V} \leftrightarrow \mathrm{d}}$ & $h_{\mathrm{v} \leftrightarrow \mathrm{d}}\left(c_{\mathrm{H}_{2} \mathrm{O}}^{d}-c_{\mathrm{H}_{2} \mathrm{O}}^{*}\right)$ & $h_{\mathrm{v} \leftrightarrow \mathrm{d}}\left(c_{\mathrm{H}_{2} \mathrm{O}}^{d}-c_{\mathrm{H}_{2} \mathrm{O}}^{*}\right)$ & 0 \\
\hline
\end{tabular}

These terms represent, from top to bottom, reactant dissolution in electrolyte, condensation/evaporation, and vapour/dissolved water mass transfer.

be determined using the same formula. The collision diameters can be approximated by

$\sigma_{\mathrm{N}_{2}, i}=\frac{1}{2}\left(\sigma_{i}+\sigma_{\mathrm{N}_{2}}\right)$

where $\sigma_{i}$ are the collision diameters for the individual species $i$. The values are given in Table 7 together with the collision integrals.

The gas velocity is given by Darcy's law for flow through a porous medium and the absolute permeability given by the Kozeny-Carman law:

$v_{\mathrm{g}}=-\frac{\kappa}{\mu}(1-s)^{3} \frac{\partial p_{\mathrm{g}}}{\partial y}, \quad \kappa=\frac{d^{2}}{K} \frac{\epsilon^{3}}{(1-\epsilon)^{2}}$,

where $\kappa$ is the absolute permeability of the gas diffusion or catalyst layers, $\mu$ is the dynamic viscosity of the gas, $d$ is a mean pore diameter and $K$ is the Kozeny-Carman constant. The source terms are given in Table $1 . S_{p i}$ is the rate of mass transfer between the electrolyte and gas phases, $S_{\mathrm{v} \leftrightarrow 1}$ is the rate of condensation/evaporation, and $S_{\mathrm{v} \leftrightarrow \mathrm{d}}$ is the rate of water mass transfer between the electrolyte and gas phases. In Table $1 h_{\mathrm{pe}, i}$ are volumetric mass-transfer coefficients from the gas to the membrane or electrolyte phase on the gas side and $H_{i}$ are dimensionless Henry constants. Each $h_{\mathrm{pe}, i}$ is approximated based on a local Sherwood number of 2 (for flow past a spherical particle [29]):

$h_{\mathrm{pe}, i}=\frac{a S h D_{i}}{d} \geq O\left(10^{5}\right)$,

where $a$ is the specific surface area of the agglomerates. The condensation/evaporation coefficient $h_{\mathrm{v} \leftrightarrow 1}$ is defined later. The quantity $v=1800 \mathrm{~mol} \mathrm{~m}^{-3}$ is the fixed-charge site concentration of the membrane,

The electrolyte volume fraction, $\epsilon_{\mathrm{e}}$, has two components: one from the films that coat the agglomerates $\left(\epsilon_{\mathrm{e}}^{f}\right)$ and the other from the electrolyte contained in the agglomerate interiors $\left(\epsilon_{\mathrm{e}}^{i}\right)$, with:

$\epsilon_{\mathrm{e}}=\epsilon_{\mathrm{e}}^{f}+\epsilon_{\mathrm{e}}^{i}$.

To account for the volume change due to swelling, which is assumed to impact only the film thickness, the following relationship is used:

$\epsilon_{\mathrm{e}}^{f}=\epsilon_{\mathrm{e}, 0}^{f}+0.0126 \lambda$

where $\lambda$ is the membrane water content $\left(\mathrm{mol} \mathrm{H}_{2} \mathrm{O} / \mathrm{mol} \mathrm{SO}_{3}{ }^{-}\right)$and $\epsilon_{\mathrm{e}, 0}^{f}$ represents the volume fraction of film without any swelling. The latter quantity is related to the film thickness without swelling, $\delta_{\mathrm{e}, 0}$, as shown in Table 6 and derived in [23]. The platinum inside the agglomerates is assumed to be inactive and therefore not to contribute to the electrochemical reaction. Thus all reaction occurs on the agglomerate surfaces. The combined volume fraction of the carbon, platinum and small pores, $\epsilon_{\mathrm{a}}$, is assumed constant. The volume fraction of primary pores is thus $\epsilon_{p}=1-\epsilon_{\mathrm{a}}-\epsilon_{\mathrm{e}}$.

Mass balance equations for species $i=\mathrm{O}_{2}, \mathrm{H}_{2}, \mathrm{~N}_{2}, \mathrm{H}_{2} \mathrm{~S}$, $\mathrm{SO}_{3}$ dissolved in the electrolyte and membrane are derived by taking into account transport by diffusion, mass transfer to and from 
Table 2

Sources and sinks for the dissolved reactants, potential and dissolved-water Eqs. (5), (13) and (6), respectively

\begin{tabular}{llll}
\hline & $\mathrm{ACL}$ & $\mathrm{CCL}$ & Meaning \\
\hline$S_{\mathrm{O}_{2}}$ & 0 & $\frac{1}{4} q_{\mathrm{O}_{2}}$ & $\mathrm{O}_{2}$ consumption \\
$S_{\mathrm{H}_{2}}$ & $a\left(-q_{3}+\frac{3}{2} q_{2}\right)$ & 0 & $\mathrm{H}_{2}$ consumption \\
$S_{\mathrm{N}_{2}}$ & 0 & 0 & $\mathrm{~N}_{2}$ \\
& & & consumption \\
$S_{\mathrm{H}_{2} \mathrm{~S}}$ & $-a\left(q_{1}+q_{2}+q_{5}\right)$ & 0 & $\mathrm{H}_{2} \mathrm{~S}$ \\
$S_{\mathrm{SO}_{3}}$ & $a q_{7}$ & 0 & consumption \\
$S_{\mathrm{e}}$ & $a F\left(q_{4}+2 q_{5}+6 q_{7}\right)$ & $\mathrm{F}_{\mathrm{O}_{2}}$ & SO $\mathrm{O}_{3}$ production \\
$S_{\mathrm{S}}$ & $-S_{\mathrm{e}}$ & $-S_{\mathrm{e}}$ & Proton source \\
$S_{\mathrm{d} \leftrightarrow 1}$ & $h_{\mathrm{d} \leftrightarrow 1}\left(c_{\mathrm{H}_{2} \mathrm{O}}^{d}-c_{\mathrm{H}_{2} \mathrm{O}}^{l}\right)$ & $h_{d \leftrightarrow l}\left(c_{\mathrm{H}_{2} \mathrm{O}}^{d}-c_{\mathrm{H}_{2} \mathrm{O}}^{l}\right)$ & Electron source \\
& & & Liquid/dissolved \\
& & & water mass \\
$S_{\mathrm{W}}$ & $-3 a q_{7}$ & $-\frac{1}{2} q_{\mathrm{O}_{2}}$ & transfer \\
& & & Water \\
& & & production \\
(liquid phase)
\end{tabular}

The last term represents liquid-water production in Eq. (8).

the gas phase, and consumption or generation by reaction:

$\frac{\partial}{\partial t}\left(\epsilon c_{i}^{d}\right)-\frac{\partial}{\partial y}\left(\epsilon^{3 / 2} D_{i}^{d} \frac{\partial c_{i}^{d}}{\partial y}\right)=S_{i}+S_{p i}$,

where $\epsilon=\epsilon_{\mathrm{e}}$ in the catalyst layer, $\epsilon=1$ in the membrane and $D_{i}^{d}$ are the free-space diffusion coefficients in the electrolyte used with Bruggeman corrections. The source terms $S_{i}, i=\mathrm{O}_{2}, \mathrm{H}_{2}, \mathrm{~N}_{2}, \mathrm{H}_{2} \mathrm{~S}$, $\mathrm{SO}_{3}$, are defined in Table 2 and are the rates of consumption or generation of species $i$. The surface reaction rates $q$ and the volumetric reaction rate $q_{\mathrm{O}_{2}}$ will be defined in Section 2.2.

The mass balance for water dissolved in the electrolyte and membrane, normalised with respect to $v, c_{\mathrm{H}_{2} \mathrm{O}}^{d}$, is derived by considering movement by diffusion and drag:

$$
\begin{aligned}
& \frac{\partial}{\partial t}\left(\epsilon c_{\mathrm{H}_{2} \mathrm{O}}^{d}\right)-\frac{\partial}{\partial y}\left(\epsilon^{3 / 2} D_{\mathrm{H}_{2} \mathrm{O}}^{d} \frac{\partial c_{\mathrm{H}_{2} \mathrm{O}}^{d}}{\partial y}+\frac{5 \lambda}{44 F \nu} \epsilon^{3 / 2} \sigma_{\mathrm{e}} \frac{\partial \phi_{\mathrm{e}}}{\partial y}\right) \\
& =-S_{\mathrm{v} \leftrightarrow \mathrm{d}}-S_{\mathrm{d} \leftrightarrow 1},
\end{aligned}
$$

in which $\epsilon=1$ for the membrane and $\epsilon=\epsilon_{\mathrm{e}}$ for the catalyst layer, and $D_{\mathrm{H}_{2} \mathrm{O}}^{d}$ is the diffusion coefficient of water in the electrolyte subject to a Bruggeman correction.

The following form of $D_{\mathrm{H}_{2} \mathrm{O}}^{d}$ for Nafion is taken from [30]:

$D_{\mathrm{H}_{2} \mathrm{O}}^{d}=u_{1} \lambda\left(1+161 \mathrm{e}^{-\lambda}\right) \exp \left(-\frac{2436}{T}\right)$,

where $u_{1}=4.17 \times 10^{-8} \mathrm{~m}^{2} \mathrm{~s}^{-1}$. The source term $S_{\mathrm{v} \leftrightarrow \mathrm{d}}$ was previously defined and $S_{\mathrm{d} \leftrightarrow 1}$, given in Table 2 , is the rate of water mass transfer between the liquid and dissolved phases. Both are discussed below. Note that the water content and concentration are related by

$\lambda=\frac{c_{\mathrm{H}_{2} \mathrm{O}}^{d}}{u_{2}-0.0126 c_{\mathrm{H}_{2} \mathrm{O}}^{d}}$,

where $u_{2}=1 \mathrm{~mol} \mathrm{~m}^{-3}$. Eq. (7) will be used in the sequel.

A mass balance of liquid water is derived considering transport by convection, driven by pressure gradients:

$\frac{\epsilon \rho_{\mathrm{l}}}{M_{\mathrm{H}_{2} \mathrm{O}}} \frac{\partial s}{\partial t}+\frac{\partial}{\partial y}\left(\frac{\epsilon \rho_{\mathrm{l}}}{M_{\mathrm{H}_{2} \mathrm{O}}} v_{\mathrm{l}}\right)=-S_{\mathrm{v} \leftrightarrow 1}+v S_{\mathrm{d} \leftrightarrow 1}+S_{\mathrm{w}}$,

where the liquid-water interstitial velocity $v_{\mathrm{l}}$ is given by Darcy's law:

$v_{1}=-\frac{\kappa s^{3}}{\mu_{1}} \frac{\partial p}{\partial y}$.
$\epsilon=\epsilon_{\mathrm{G}}$ in the gas diffusion layers and $\epsilon=\epsilon_{p}$ in the catalyst layers. $M_{\mathrm{H}_{2} \mathrm{O}}, \mu_{1}$ and $p$ are the molar mass, viscosity and pressure of the liquid water, respectively, and $\kappa$ is the absolute permeability of the catalyst or gas diffusion layers. The factor of $s^{3}$ in Eq. (9) is the relative permeability. The source term $S_{\mathrm{w}}$ is defined in Table 2 and is the rate of liquid-water production.

By definition:

$p=p_{\mathrm{g}}-p_{\text {cap }}$,

where $p_{\text {cap }}$ is the capillary pressure. Combining Eqs. (8), (9) and (10) yields:

$$
\begin{aligned}
& \frac{\epsilon \rho_{\mathrm{l}}}{M_{\mathrm{H}_{2} \mathrm{O}}} \frac{\partial s}{\partial t}+\frac{\epsilon \kappa \rho_{\mathrm{l}}}{\mu_{\mathrm{l}} M_{\mathrm{H}_{2} \mathrm{O}}} \frac{\partial}{\partial y}\left(s^{3}\left(\frac{\mathrm{d} p_{\mathrm{cap}}}{\mathrm{d} s} \frac{\partial s}{\partial y}-\frac{\partial p_{\mathrm{g}}}{\partial y}\right)\right) \\
& =-S_{\mathrm{v} \leftrightarrow 1}+\nu S_{\mathrm{d} \leftrightarrow 1}+S_{\mathrm{w}} .
\end{aligned}
$$

For a discussion on the form of the permeability and capillary pressure the reader is referred to [26]. In this paper the widely used Leverette function is adopted (found in, for example [31]):

$$
\begin{aligned}
& p_{\text {cap }}=\sigma^{\prime} \cos \chi_{\mathrm{G}} \sqrt{\frac{\epsilon_{\mathrm{G}}}{\kappa_{\mathrm{G}}}} \mathcal{J}(1-s), \\
& p_{\text {cap }}=\sigma^{\prime} \cos \chi_{\mathrm{C}} \sqrt{\frac{\epsilon_{p}}{\kappa_{\mathrm{C}}}} \mathcal{J}(s),
\end{aligned}
$$

for the gas diffusion and catalyst layers, respectively. In these expressions $\sigma^{\prime}$ is the surface tension and $\mathcal{J} \xi$ ) is the Leverette function:

$\mathcal{J}(\xi)=1.417 \xi-2.12 \xi^{2}+1.262 \xi^{3}$

$\chi_{\mathrm{C}}$ and $\kappa_{\mathrm{C}}$ are the contact angle and absolute permeability of the catalyst layers, respectively, and $\chi_{\mathrm{G}}$ and $\kappa_{\mathrm{G}}$ are the contact angle and absolute permeability of the gas diffusion layers, respectively.

\subsubsection{Charge conservation}

Equations for the potentials in the electrolyte/membrane and carbon, $\phi_{\mathrm{e}}$ and $\phi_{\mathrm{s}}$ respectively, are derived from conservation of charge in each phase, assuming electroneutrality and steady-state conditions, as justified in the assumptions:

$-\frac{\partial}{\partial y}\left(\epsilon^{3 / 2} \sigma_{\mathrm{e}} \frac{\partial \phi_{\mathrm{e}}}{\partial y}\right)-S_{\mathrm{e}}=-\frac{\partial}{\partial y}\left(\epsilon^{3 / 2} \sigma_{\mathrm{s}} \frac{\partial \phi_{\mathrm{s}}}{\partial y}\right)+S_{\mathrm{s}}=0$,

where $\sigma_{\mathrm{e}}$ and $\sigma_{\mathrm{s}}$ are the protonic and electronic conductivity respectively, used with Bruggeman corrections, and $F$ is Faraday's constant. $\epsilon=\epsilon_{\mathrm{e}}$ in the catalyst layer and $\epsilon=1$ in the membrane for $\phi_{\mathrm{e}}$, while $\epsilon=1-\epsilon_{\mathrm{G}}$ in the gas diffusion layer and $\epsilon=\epsilon_{\mathrm{s}}$ in the catalyst layer for $\phi_{\mathrm{s}}$. The source terms $S_{\mathrm{s}}$ and $S_{\mathrm{e}}$ are defined in Table 2 . The protonic conductivity is assumed to take the form given in [32] for Nafion:

$\sigma_{\mathrm{e}}=u_{3} \exp \left(\frac{1286}{303}-\frac{1286}{T}\right)(0.514 \lambda-0.326)$,

where $u_{3}=1 \mathrm{~S} \mathrm{~m}^{-1}$. The electronic conductivity is constant and its value is given in Table 10. 
Table 3

Sources and sinks for the energy Eq. (15)

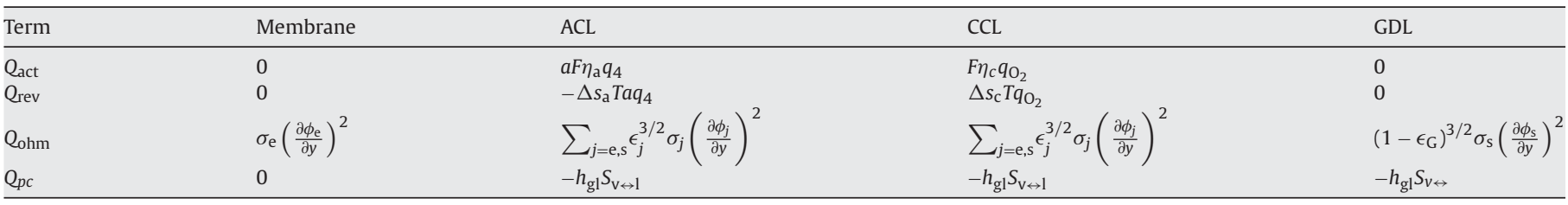

They are, from top to bottom, activation losses, heats of reaction, ohmic losses and heats of evaporation.

\subsubsection{Energy conservation}

A thermal energy balance equation is derived by taking into account heat generation and heat transport through the gas, liquid and solid phases, and assuming a single temperature:

$\frac{\partial}{\partial t}\left(\widehat{\rho C_{p}} T\right)+\frac{\partial}{\partial y}\left(\epsilon s \rho_{\mathrm{l}} C_{\mathrm{l}} v_{\mathrm{l}} T+\epsilon(1-s) \rho_{\mathrm{g}} C_{\mathrm{g}} v_{\mathrm{g}} T-\hat{k} \frac{\partial T}{\partial y}\right)=\sum_{k} Q_{k}$,

in the catalyst and gas diffusion layers, and

$\frac{\partial}{\partial t}\left(\rho_{\mathrm{m}} C_{\mathrm{m}} T\right)+\frac{\partial}{\partial y}\left(k_{\mathrm{m}} \frac{\partial T}{\partial y}\right)=\sum_{k} Q_{k}$,

in the membrane. In these equations $\rho_{\mathrm{l}}, \rho_{\mathrm{g}}, \rho_{\mathrm{m}}$ and $\rho_{\mathrm{s}}$ are the densities of the liquid, gas, membrane and solid phases, respectively, and $C_{1}, C_{\mathrm{g}}, C_{\mathrm{m}}$ and $C_{\mathrm{s}}$ are the specific heat capacities of the liquid, gas, membrane and solid phases, respectively. $\hat{k}$ and $\widehat{\rho C}_{p}$ are the volume-averaged thermal conductivity and thermal capacitance:

$\hat{k}=k_{p}(1-s) \epsilon+k_{1} s \epsilon+k_{s}(1-\epsilon)$,

$\widehat{\rho C_{p}}=\epsilon s \rho_{\mathrm{l}} C_{\mathrm{l}}+\epsilon(1-s) \rho_{\mathrm{g}} C_{\mathrm{g}}+\rho_{\mathrm{s}} C_{\mathrm{s}}(1-\epsilon)$,

where $k_{p}, k_{\mathrm{s}}$ and $k_{\mathrm{l}}$ are the thermal conductivities of the pore space, solid (averaged over carbon, electrolyte and platinum) and liquid water, respectively. In the gas diffusion layers $\epsilon=\epsilon_{\mathrm{G}}$ and in the catalyst layers $\epsilon=\epsilon_{p}$. In the membrane the only form of heat transport is conduction. The gas phase thermal conductivity and specific heat capacity are approximated by values for air. The heat generation terms $Q_{k}$ are defined in Table 3. In these expressions $h_{\mathrm{gl}}$ is the liquid-gas enthalpy change for water, $-\Delta s_{\mathrm{c}}$ is the entropy associated with the oxygen reduction reaction and $-\Delta s_{\mathrm{a}}$ is the entropy associated with the hydrogen oxidation reaction. Note that as a simplification, the heats of reaction of the other anode reactions are neglected.

\subsubsection{Water phase change}

The treatment of water mass transfer between the three phases is now detailed. Condensation and evaporation are driven by the deviation from equilibrium: $x_{v} p_{\mathrm{g}}-p_{\text {sat }}$, where $p_{\text {sat }}$ is the saturation pressure of water and the first term, in which $x_{v}$ is the vapour mole fraction, is the partial pressure of the vapour. The condensation/evaporation coefficient $h_{\mathrm{v} \leftrightarrow l}$ in Table 1 takes the form:

$h_{\mathrm{v} \leftrightarrow \mathrm{l}}= \begin{cases}h_{\text {cond }} \frac{\epsilon_{p}(1-s) x_{v}}{R T} & x_{v} p_{\mathrm{g}}-p_{\text {sat }}>0 \\ h_{\mathrm{evap}} \frac{\epsilon_{p} s \rho_{\mathrm{l}}}{M_{\mathrm{H}_{2} \mathrm{O}}} & x_{v} p_{\mathrm{g}}-p_{\text {sat }}<0\end{cases}$

$h_{\text {cond }}$ and $h_{\text {evap }}$ are the condensation and evaporation rate constants, whose values are taken from [25].

In a similar fashion, the vapour-dissolved phase-change term in Eqs. (2) and (6), $S_{\mathrm{v} \leftrightarrow \mathrm{d}}$, is driven by the deviation from equilibrium between the vapour and dissolved water, $c_{\mathrm{H}_{2} \mathrm{O}}^{d}-c_{\mathrm{H}_{2} \mathrm{O}}^{*}$, where $c_{\mathrm{H}_{2} \mathrm{O}}^{*}$ is the dissolved water concentration at equilibrium, as given in [33]:

$\lambda^{*}=0.3+10.8 a_{\mathrm{w}}-16 a_{\mathrm{w}}^{2}+14.1 a_{\mathrm{w}}^{3}$, or, equivalently:

$c_{\mathrm{H}_{2} \mathrm{O}}^{*}\left(u_{2}+0.0126 \lambda^{*}\right)=\lambda^{*}$.

In these formulae, $a_{\mathrm{w}}=x_{v} p_{\mathrm{g}} / p_{\text {sat }}$ is the water vapour activity. The mass-transfer coefficient $h_{\mathrm{v} \leftrightarrow \mathrm{d}}$ is approximated from the results in [34]:

$h_{\mathrm{v} \leftrightarrow \mathrm{d}}= \begin{cases}h_{\mathrm{ads}, v}(1-s) \lambda & c_{\mathrm{H}_{2} \mathrm{O}}^{d}-c_{\mathrm{H}_{2} \mathrm{O}}^{*}<0 \\ h_{\mathrm{des}, v}(1-s) \lambda & c_{\mathrm{H}_{2} \mathrm{O}}^{d}-c_{\mathrm{H}_{2} \mathrm{O}}^{*}>0,\end{cases}$

where $h_{\mathrm{des}, v}$ and $h_{\mathrm{ads}, v}$ are desorption and adsorption coefficients, respectively. Their values are given in Table 10 .

The equilibrium membrane water content depends on its environment, with either relationship (19) for contact with vapour or $\lambda=\lambda^{l}=16.8$ for contact with liquid water. Note that the liquidequilibrated dissolved water concentration, $c_{\mathrm{H}_{2} \mathrm{O}}^{l}$, is given by Eq. (7):

$c_{\mathrm{H}_{2} \mathrm{O}}^{l}=\frac{\lambda^{l}}{u_{2}+0.0126 \lambda^{l}}$.

The discontinuity between the vapour-saturated and liquid values is known as Schroeder's paradox. The mass-transfer term $S_{\mathrm{d} \leftrightarrow 1}$ in Eqs. (6) and (8), and Table 2, is decomposed into terms for absorption and desorption of liquid water to and from the electrolyte in the catalyst layer. When the liquid-equilibrated water content value $c_{\mathrm{H}_{2} \mathrm{O}}^{l}$ is reached or exceeded, it is assumed that desorption of water from the electrolyte takes place (as liquid), the magnitude of which is driven by $c_{\mathrm{H}_{2} \mathrm{O}}^{d}-c_{\mathrm{H}_{2} \mathrm{O}}^{l}$. Adsorption is assumed to take place for $c_{\mathrm{H}_{2} \mathrm{O}}^{d}<c_{\mathrm{H}_{2} \mathrm{O}}^{l}$ provided $s>s_{*}$, where $s_{*}$ is the immobile saturation. The coefficient $h_{\mathrm{d} \leftrightarrow 1}$ in Table 2 therefore takes the form:

$h_{\mathrm{d} \leftrightarrow \mathrm{l}}=h_{\mathrm{des}, \mathrm{l}} H\left(c_{\mathrm{H}_{2} \mathrm{O}}^{d}-c_{\mathrm{H}_{2} \mathrm{O}}^{l}\right)+h_{\mathrm{ads}, 1} H\left(s-s_{*}\right) H\left(-c_{\mathrm{H}_{2} \mathrm{O}}^{d}+c_{\mathrm{H}_{2} \mathrm{O}}^{l}\right)$,

where $H(\cdot)$ is the Heaviside function and $h_{\mathrm{des}, \mathrm{l}}$ and $h_{\mathrm{ads}, \mathrm{l}}$ are the coefficients of desorption and absorption, which, for simplicity, are assumed to be constant. Their values are given in Table 10.

\subsection{Reaction kinetics}

The reaction rates appearing in Tables 2 and 3 are yet to be defined. The kinetics at the cathode are approximated by the following global, one-step reaction:

Oxygen reduction reaction (ORR) : $\mathrm{O}_{2}+4 \mathrm{H}^{+}+4 \mathrm{e}^{-} \rightleftharpoons 2 \mathrm{H}_{2} \mathrm{O}$,

for which we use the Butler-Volmer law (in mol $\mathrm{m}^{-3} \mathrm{~s}^{-1}$ ):

$q_{\mathrm{O}_{2}}\left(\eta_{\mathrm{c}}, T, c_{\mathrm{O}_{2}}^{s}\right)=\frac{a j_{\mathrm{O}_{2}, \text { ref }}}{F c_{\mathrm{O}_{2}, \mathrm{ref}}} \epsilon_{\mathrm{e}} c_{\mathrm{O}_{2}}^{s}\left\{\exp \left(\frac{\alpha_{\mathrm{a}} F \eta_{\mathrm{c}}}{R T}\right)-\exp \left(-\frac{\alpha_{\mathrm{c}} F \eta_{\mathrm{c}}}{R T}\right)\right\}$.

The various terms in the formula are the exchange current density $j_{\mathrm{O}_{2} \text {,ref }}$; the anodic and cathodic transfer coefficients $\alpha_{\mathrm{a}}$ and $\alpha_{\mathrm{c}}$, 
respectively; the reference oxygen molar concentration $c_{\mathrm{O}_{2} \text {,ref }}$; the volumetric specific surface area of catalyst (per unit volume of catalyst layer) $a$; and the overpotential $\eta_{\mathrm{c}}$. The expression

$a=\frac{a_{\mathrm{pt}} m_{\mathrm{pt}}}{L}$

relates the specific surface area of platinum to the mass specific platinum surface area (platinum surface area per unit mass of platinum), $a_{\mathrm{pt}}$, the platinum loading, $m_{\mathrm{pt}}$, and the catalyst layer thickness, $L$. The overpotentials in the cathode and anode, $\eta_{\mathrm{c}}$ and $\eta_{\mathrm{a}}$ respectively, are defined as

$\eta_{\mathrm{c}}=\phi_{\mathrm{s}}-\phi_{\mathrm{e}}-E_{0}, \quad \eta_{\mathrm{a}}=\phi_{\mathrm{s}}-\phi_{\mathrm{e}}$,

where $E_{0}$ is the open circuit potential vs. S.H.E. [35]:

$E_{0}=1.23-9 \times 10^{-4}(T-298.15)$.

An agglomerate model is used for the cathode catalyst layer, in which $c_{\mathrm{O}_{2}}^{s}$ is the oxygen concentration at the agglomerate surfaces. It is related to the bulk value, $c_{\mathrm{O}_{2}}$, by balancing the rate of reaction with the rate of diffusion of reactant through electrolyte and water films to the surfaces of the agglomerates. The final form of the reaction rate is

$q_{\mathrm{O}_{2}}=4 \gamma a^{\prime} c_{\mathrm{O}_{2}} \frac{\mathrm{e}^{\alpha_{\mathrm{a}} F \eta_{\mathrm{c}} / R T}-\mathrm{e}^{-\alpha_{\mathrm{c}} F \eta_{\mathrm{c}} / R T}}{\gamma+a^{\prime}\left(\mathrm{e}^{\alpha_{\mathrm{a}} F \eta_{\mathrm{c}} / R T}-\mathrm{e}^{-\alpha_{\mathrm{c}} F \eta_{\mathrm{c}} / R T}\right)}$,

where the parameter $a^{\prime}$ is given by

$a^{\prime}=\frac{a j_{\mathrm{O}_{2}, \text { ref }}}{4 F c_{\mathrm{O}_{2}, \text { ref }}}$

$\gamma$ is a measure of the diffusion rate through the films $(\gamma / a$ is the piston velocity) and takes the form:

$\gamma=\frac{\left(A^{\prime} D_{\mathrm{l}} / \delta_{\mathrm{l}}\right)\left(A D_{\mathrm{O}_{2}}^{d} / \delta_{\mathrm{e}}\right)}{A^{\prime} D_{\mathrm{l}} / \delta_{\mathrm{l}}+A D_{\mathrm{O}_{2}}^{d} / \delta_{\mathrm{e}}}$,

in which $A^{\prime}=4 \pi\left(R_{\mathrm{agg}}+\delta_{\mathrm{e}}\right)^{2} N$. In these expressions: $\delta_{\mathrm{e}}$ and $\delta_{\mathrm{l}}$ are the electrolyte and liquid-water film thicknesses respectively; $N$ is the number of agglomerates per unit volume; $A=4 \pi R_{\mathrm{agg}}^{2} N$ is the specific surface area of agglomerates, assuming that the entire surface area of each agglomerate is covered; $R_{\mathrm{agg}}$ is the agglomerate radius; and $D_{1}$ is the diffusion coefficient of $\mathrm{O}_{2}$ through liquid water. The film thicknesses, $\delta_{\mathrm{e}}$ and $\delta_{\mathrm{l}}$, are defined in Table 6 and take account of electrolyte swelling. The reader is referred to [23] for derivations.

The $\mathrm{H}_{2} \mathrm{~S}$ kinetics on platinum were investigated by Contractor and Lal $[10,11]$, who suggested that there are two adsorbed forms of sulfur, one strongly and one weakly bonded. Mathieu and Primet [12], proposed the following form for the surface reactions:

$\mathrm{H}_{2} \mathrm{~S}+\mathrm{Pt} \rightleftharpoons \mathrm{Pt}-\mathrm{S}+\mathrm{H}_{2}$.

$\mathrm{Pt}-\mathrm{H}+\mathrm{H}_{2} \mathrm{~S} \rightleftharpoons \mathrm{Pt}-\mathrm{S}+\frac{3}{2} \mathrm{H}_{2}$.

These reactions occur in competition with the adsorption and electro-oxidation of hydrogen [24]:

$\mathrm{H}_{2}+2 \mathrm{Pt} \rightleftharpoons 2 \mathrm{Pt}-\mathrm{H}$.

$\mathrm{Pt}-\mathrm{H} \rightleftharpoons \mathrm{H}^{+}+\mathrm{e}^{-}+\mathrm{Pt}$.

Mohtadi et al. [1], suggested that platinum sulfide (Pt-S) can also be formed electrochemically according to reaction (R5) below. The same reaction was proposed by and Najdeker and Bishop [14], who further suggested that platinum disulfide $\left(\mathrm{Pt}-\mathrm{S}_{2}\right)$ could be formed according to reaction (R6):

$\mathrm{H}_{2} \mathrm{~S}+\mathrm{Pt} \rightleftharpoons \mathrm{Pt}-\mathrm{S}+2 \mathrm{H}^{+}+2 \mathrm{e}^{-}$.
$\mathrm{H}_{2} \mathrm{~S}+\mathrm{Pt}-\mathrm{S} \rightleftharpoons \mathrm{Pt}-\mathrm{S}_{2}+2 \mathrm{H}^{+}+2 \mathrm{e}^{-}$.

According to the cyclic-voltammetry measurements in $[10,13]$, the main species to form is in fact Pt-S.

The adsorbed sulfur can be oxidised via reaction with water as shown in reactions (R7) and (R8) below. This mechanism was proposed by Loučka [4], and confirmed by Mohtadi et al. [13] and Wang et al. [18], in which the authors report the presence of sulfate ions:

Pt-S $+3 \mathrm{H}_{2} \mathrm{O} \rightleftharpoons \mathrm{SO}_{3}+6 \mathrm{H}^{+}+6 \mathrm{e}^{-}+$Pt.

$\mathrm{Pt}-\mathrm{S}+4 \mathrm{H}_{2} \mathrm{O} \rightleftharpoons \mathrm{SO}_{4}^{2-}+8 \mathrm{H}^{+}+6 \mathrm{e}^{-}+\mathrm{Pt}$.

The mechanism considered by Shi et al. [16] is an application of the general contamination model developed in [36]. After approximation, it consists essentially of the forward parts of reactions (R1), (R3) and (R8), the competitive adsorption of $\mathrm{H}_{2}$ on platinum and the following reaction:

$\mathrm{Pt}-\mathrm{H}+\mathrm{H}_{2} \mathrm{~S} \rightarrow \mathrm{Pt}-\mathrm{S}+\mathrm{H}_{2}+\mathrm{H}^{+}+\mathrm{e}^{-}$

This reaction, though not supported by experiment, appears to have been included for consistency with the model in [36].

The model developed below includes reactions (R1)-(R7). Reaction (R6) is neglected as per the results of $[10,13]$ and reaction (R8) is neglected for simplicity. It is not expected that the overall behaviour of the system will be altered qualitatively by these assumptions. The model incorporates the two main mechanisms of adsorption and oxidation, for both hydrogen and sulfur.

Equations for the evolutions of the site coverages for atomic hydrogen and sulfur, $\theta_{\mathbf{H}}$ and $\theta_{\mathbf{S}}$ respectively, are then as follows:

$\tau \frac{\mathrm{d} \theta_{\mathrm{H}}}{\mathrm{d} t}=-q_{2}+2 q_{3}-q_{4}$

$\tau \frac{\mathrm{d} \theta_{\mathrm{S}}}{\mathrm{d} t}=q_{1}+q_{2}+q_{5}-q_{7}$

where the rates are defined by

$$
\begin{aligned}
q_{1} & =r_{1 f} c_{\mathrm{H}_{2} \mathrm{~S}}^{d} \theta_{\mathrm{Pt}} \exp \left(-\frac{\alpha_{1} i \theta_{\mathrm{S}}}{R T}\right)-r_{1 b} c_{\mathrm{H}_{2}}^{d} \theta_{\mathrm{S}} \exp \left(\frac{\left(1-\alpha_{1}\right) i \theta_{\mathrm{S}}}{R T}\right) \\
q_{2} & =r_{2 f} \theta_{\mathrm{H}} c_{\mathrm{H}_{2} \mathrm{~S}}^{d}-r_{2 b} \theta_{\mathrm{S}}\left(c_{\mathrm{H}_{2}}^{d}\right)^{3 / 2} \\
q_{3} & =r_{3 f} c_{\mathrm{H}_{2}}^{d} \theta_{\mathrm{Pt}}^{2}-r_{3 b} \theta_{\mathrm{H}}^{2} \\
q_{4} & =r_{4} \theta_{\mathrm{H}} \sinh \left(\frac{\alpha_{4} F \eta_{\mathrm{a}}}{R T}\right) \\
q_{5} & =r_{5 f} c_{\mathrm{H}_{2} \mathrm{~S}}^{d} \theta_{\mathrm{Pt}} \exp \left(\frac{2 \alpha_{5} F \eta_{\mathrm{a}}}{R T}\right)-r_{5 b} \theta_{\mathrm{S}} c_{\mathrm{H}^{+}}^{2} \\
& \times \exp \left(-\frac{2\left(1-\alpha_{5}\right) F \eta_{\mathrm{a}}}{R T}\right) \\
q_{7} & =r_{7 f}\left(c_{\mathrm{H}_{2} \mathrm{O}}^{d}\right)^{3} \theta_{\mathrm{S}} \exp \left(\frac{6 \alpha_{7} F \eta_{\mathrm{a}}}{R T}\right) \\
& -r_{7 b} c_{\mathrm{SO}_{3}}^{d} c_{\mathrm{H}^{+}}^{6} \theta_{\mathrm{Pt}} \exp \left(-\frac{6\left(1-\alpha_{7}\right) F \eta_{\mathrm{a}}}{R T}\right) .
\end{aligned}
$$

The quantity $\tau$ is the molar area density of catalyst sites. The surface coverage of free platinum sites, $\theta_{\mathrm{Pt}}$, is given by

$\theta_{\mathrm{Pt}}=1-\theta_{\mathrm{H}}-\theta_{\mathrm{S}}$

Eqs. (30) and (31) are derived on the assumption that coverage does not exceed a monolayer. The forms of the reaction rates are based on:

(1) a Frumkin isotherm for reaction (R1), sulfur adsorption and desorption, with rate $q_{1}$; 
(2) Langmuir isotherms for reaction (R2) and reaction (R3), $\mathrm{H}_{2}$ dissociative adsorption and desorption, with rates $q_{2}$ and $q_{3}$ respectively;

(3) Butler-Volmer kinetics for reaction (R4), electro-oxidation of hydrogen, with rate $q_{4}$

(4) and Butler-Volmer type kinetics for the oxidation reactions (R5) and (R7), with rates $q_{5}$ and $q_{7}$, respectively.

In the Frumkin model [37], the apparent standard free energy of adsorption is assumed to vary linearly with $\theta_{\mathrm{S}}$, with slope equal to the interaction parameter $i$, [38]. Since their values are not known, all charge transfer coefficients, $\alpha_{i}$, are assumed to be $1 / 2$. This is a common modelling assumption. It was further assumed that the backward rates for reactions (R5) and (R7) are negligibly small. The values of $r_{1 f}, r_{1 b}$ and $r_{7 f}$ were then fitted to achieve a qualitative match to experimental results in the literature. Similar fitting procedures have been performed in $[3,6,7,16]$.

\subsection{Initial and boundary conditions}

At the interfaces between the membrane and catalyst layers, $y=y_{2}$ and $y=y_{3}$ shown in Fig. 1, the gas-phase and liquid-water fluxes are taken to be zero. Similarly, the fluxes of protons and dissolved species at the interfaces between the catalyst and gas diffusion layers, $y=y_{1}$ and $y=y_{4}$, are negligibly small:

$y=y_{1}, y_{4}:\left\{\begin{array}{l}\epsilon^{3 / 2} D_{i}^{d} \frac{\partial c_{i}^{d}}{\partial y}=0 \\ \epsilon^{3 / 2} \sigma_{\mathrm{e}} \frac{\partial \phi_{\mathrm{e}}}{\partial y}=0 \\ D_{\mathrm{H}_{2} \mathrm{O}}^{d} \frac{\partial c_{\mathrm{H}_{2} \mathrm{O}}^{d}}{\partial y}+\frac{5 \lambda \sigma_{\mathrm{e}}}{44 F v} \frac{\partial \phi_{\mathrm{e}}}{\partial y}=0\end{array}\right.$

$y=y_{2}, y_{3}:\left\{\begin{array}{l}D_{i} \frac{\partial c_{i}}{\partial y}-v_{\mathrm{g}} c_{i}=0 \\ \frac{\partial s}{\partial y}=0\end{array}\right.$

At the interfaces between the channels and gas diffusion layers, the gas mole fractions are prescribed or calculated from the other conditions:

$x_{i}=\left\{\begin{array}{ll}\bar{x}_{i, \mathrm{c}} & y=y_{0} \\ \bar{x}_{i, \mathrm{a}} & y=y_{5}\end{array}, \quad i=\mathrm{H}_{2}, \mathrm{O}_{2}, \mathrm{H}_{2} \mathrm{~S}_{3} \mathrm{SO}_{3}, \mathrm{~N}_{2}, \mathrm{H}_{2} \mathrm{O}\right.$.

Likewise, temperature, water activity and pressure are prescribed according to the channel values:

$T\left(y_{0}\right)=T_{\mathrm{c}} \quad T\left(y_{5}\right)=T_{\mathrm{a}}$,

$p_{\mathrm{g}}\left(y_{0}\right)=p_{\mathrm{c}} \quad p_{\mathrm{g}}\left(y_{5}\right)=p_{\mathrm{a}}$,

$a_{\mathrm{w}}\left(y_{0}\right)=a_{\mathrm{w}, \mathrm{c}} \quad a_{\mathrm{w}}\left(y_{5}\right)=a_{\mathrm{w}, \mathrm{a}}$.

The concentrations of water vapour in the cathode and anode channels, $\bar{c}_{v, \mathrm{c}}$ and $\bar{c}_{v, \mathrm{a}}$ respectively, are calculated from the water activities and saturation pressures ([32]):

$$
\begin{aligned}
\log _{10} p_{\text {sat }}=-2.1794 & +0.02953(T-273.15) \\
& -9.1837 \times 10^{-5}(T-273.15)^{2} \\
& +1.4454 \times 10^{-7}(T-273.15)^{3},
\end{aligned}
$$

in bars, yielding:

$\bar{c}_{v, \mathrm{c}}=\frac{a_{\mathrm{w}, \mathrm{c}} p_{\mathrm{sat}, \mathrm{c}}}{R T_{\mathrm{c}}}$ or $\quad \bar{x}_{v, \mathrm{c}}=\frac{a_{\mathrm{w}, \mathrm{c}} p_{\mathrm{sat}, \mathrm{c}}}{p_{\mathrm{c}}}$

where $p_{\text {sat,c }}$ is the cathode-channel saturation pressure (expressed in Pa). A similar calculation applies on the anode side where the channel saturation pressure is $p_{\text {sat,a }}$.

\begin{tabular}{|c|c|c|}
\hline Symbol & Quantity & Size \\
\hline$T_{\mathrm{C}}$ & Cathode channel temperature & $60^{\circ} \mathrm{C}$ \\
\hline$T_{\mathrm{a}}$ & Anode channel temperature & $60^{\circ} \mathrm{C}$ \\
\hline$a_{\mathrm{w}, \mathrm{c}}$ & Cathode channel water activity & 0.9 \\
\hline$a_{\mathrm{w}, \mathrm{a}}$ & Anode channel water activity & 0.9 \\
\hline $\bar{x}_{\mathrm{O}_{2}, \mathrm{c}}$ & Oxygen mole fraction in cathode channel ${ }^{\mathrm{a}}$ & 0.21 \\
\hline $\bar{x}_{\mathrm{H}_{2}, \mathrm{a}}$ & Hydrogen mole fraction in anode channel $^{\mathrm{a}}$ & 0.4 \\
\hline $\bar{x}_{\mathrm{SO}_{3}, \mathrm{a}}$ & $\mathrm{SO}_{3}$ mole fraction in anode channel ${ }^{\mathrm{a}}$ & 0 \\
\hline $\bar{x}_{\mathrm{N}_{2}, \mathrm{c}}$ & Nitrogen mole fraction in cathode channel ${ }^{\mathrm{a}}$ & 0.79 \\
\hline $\bar{x}_{\mathrm{N}_{2}, \mathrm{a}}$ & Nitrogen mole fraction in anode channel ${ }^{\mathrm{a}}$ & 0.6 \\
\hline $\bar{c}_{\mathrm{H}_{2} \mathrm{~S}, \mathrm{a}}$ & $\mathrm{H}_{2} \mathrm{~S}$ mole fraction in anode channel $^{\mathrm{a}}$ & $2 \mathrm{ppm}$ \\
\hline$p_{\mathrm{c}}$ & Gas pressure in the cathode channel & $300 \mathrm{kPa}$ \\
\hline$p_{\mathrm{a}}$ & Gas pressure in the anode channel & $300 \mathrm{kPa}$ \\
\hline $\bar{c}_{\mathrm{H}_{2} \mathrm{O}, \mathrm{c}}$ & Vapour concentration in cathode channel & $6.38 \mathrm{~mol} \mathrm{~m}^{-3}$ \\
\hline $\bar{c}_{\mathrm{H}_{2} \mathrm{O}, \mathrm{a}}$ & Vapour concentration in the anode channel & $6.38 \mathrm{~mol} \mathrm{~m}^{-3}$ \\
\hline$\beta_{j}$ & Liquid-water removal constants (anode and cathode) ${ }^{\mathrm{a}}$ & $0.075 \mathrm{~m}^{-1}$ \\
\hline$j_{\mathrm{a}}$ & Applied current density & $0.5 \mathrm{Acm}^{-2}$ \\
\hline$E$ & Cell voltage & $0.5 \mathrm{~V}$ \\
\hline
\end{tabular}

Table 4

Operating conditions assumed in the calculations, unless otherwise specified

a After subtracting the vapour concentration.

For operation in the potentiostatic mode the cell voltage, $E$, is prescribed at the cathode channel/gas diffusion layer interface, and at the anode channel/gas diffusion layer interface the electronic potential is assigned a value of zero:

$\phi_{\mathrm{s}}\left(y_{0}\right)=E, \quad \phi_{\mathrm{s}}\left(y_{5}\right)=0$.

When the cell is operated in galvanostatic mode, a current density $j_{\mathrm{a}}$ is prescribed at the electrode/gas channel interfaces:

$-\sigma_{p} \frac{\partial \phi_{\mathrm{s}}}{\partial y}= \begin{cases}j_{\mathrm{a}} & y=0 \\ -j_{\mathrm{a}} & y=y_{5}\end{cases}$

where $\sigma_{p}$ is the electronic conductivity of the current collector (plate).

The final boundary conditions are those for liquid water at the interfaces between the gas channels and the gas diffusion layer.

\begin{tabular}{|c|c|c|}
\hline Symbol & Quantity & Size \\
\hline$L$ & Catalyst layer thickness & $25 \mu \mathrm{m}$ \\
\hline$L_{\mathrm{m}}$ & Membrane thickness & $50 \mu \mathrm{m}$ \\
\hline$L_{\mathrm{G}}$ & GDL thickness & $200 \mu \mathrm{m}$ \\
\hline$\epsilon_{\mathrm{e}}^{i}$ & $\begin{array}{l}\text { Electrolyte volume fraction in } \\
\text { agglomerates }^{\mathrm{a}}\end{array}$ & 0.15 \\
\hline$\epsilon_{\mathrm{a}}$ & $\begin{array}{l}\text { Volume fraction of agglomerates } \\
{[40]}\end{array}$ & 0.4215 \\
\hline$\epsilon_{\mathrm{S}}$ & Volume fraction of carbon in $\mathrm{CL}^{\mathrm{b}}$ & 0.2 \\
\hline$\epsilon_{\mathrm{G}}$ & Porosity of the GDL [41] & 0.74 \\
\hline$R_{\text {agg }}$ & Agglomerate radius [40] & $0.5 \mu \mathrm{m}$ \\
\hline$\delta_{\mathrm{e}, 0}$ & $\begin{array}{l}\text { Electrolyte film thickness without } \\
\text { swelling [23] }\end{array}$ & $0.1 \mu \mathrm{m}$ \\
\hline$\epsilon_{\mathrm{e}, 0}^{f}$ & $\begin{array}{l}\text { Electrolyte volume fraction } \\
\text { without swelling [23] }\end{array}$ & $\frac{4 \pi N}{3}\left[\left(R_{\mathrm{agg}}+\delta_{\mathrm{e}, 0}\right)^{3}-R_{\mathrm{agg}}^{3}\right]$ \\
\hline$\delta_{\mathrm{e}}$ & Electrolyte film thickness [m] [23] & $\sqrt[3]{R_{\mathrm{agg}}^{3}+\frac{3 \epsilon_{\mathrm{e}}^{f}}{4 \pi N}}-R_{\mathrm{agg}}$ \\
\hline$\delta_{1}$ & $\begin{array}{l}\text { Water film thickness [m]: } \\
R_{\delta}=R_{\mathrm{agg}}+\delta_{\mathrm{e}}[23]\end{array}$ & $\sqrt[3]{R_{\delta}^{3}+\frac{3 s \epsilon_{p}}{4 \pi N}}-R_{\delta}$ \\
\hline$N$ & Agglomerate density ${ }^{\mathrm{b}}$ & $5.8 \times 10^{17} \mathrm{~m}^{-3}$ \\
\hline$a_{\mathrm{pt}}$ & $\begin{array}{l}\text { Specific surface area of platinum } \\
{[42]}\end{array}$ & $1000 \mathrm{~cm}^{2}(\mathrm{mg} \mathrm{Pt})^{-1}$ \\
\hline$m_{\mathrm{pt}}$ & Platinum loading ${ }^{\mathrm{a}}$ & $0.4(\mathrm{mg} \mathrm{Pt}) \mathrm{cm}^{-2}$ \\
\hline$\chi_{c}$ & Catalyst-layer contact angle [43] & $90^{\circ}$ \\
\hline$\chi_{G}$ & $\begin{array}{l}\text { Gas diffusion layer contact angle } \\
\text { [43] }\end{array}$ & $120^{\circ}$ \\
\hline$d_{\mathrm{G}}$ & GDL pore size $\mathrm{a}^{\mathrm{a}}$ & $10 \mu \mathrm{m}$ \\
\hline$d_{C}$ & Catalyst-layer pore size $\mathrm{a}^{\mathrm{a}}$ & $2 \mu \mathrm{m}$ \\
\hline
\end{tabular}

Table 5

The default parameter values relating to structural properties

a Assumed value.

b Estimated value. 
They are approximated using the following steady-state flux conditions at $y=y_{0}$ and $y=y_{5}$ (see [23] for details):

$$
\frac{\partial s}{\partial y}-\beta_{j} s=0, \quad j=\mathrm{a}, \mathrm{c},
$$

where $\beta_{j}=0$ corresponds to zero water removal from the anode channel, $j=\mathrm{a}$, or cathode channel, $j=\mathrm{c}$.

The initial conditions for the pressures, temperatures and vapour concentrations are consistent with the conditions in the channels. The electronic potential at the initial time is given by the open-circuit potential at the cathode and is zero at the anode. The initial protonic potential is zero in all regions. The cell voltage or current is ramped at a finite rate as discussed later. The initial water content of the membrane/electrolyte is given by equilibrium with the vapour in the channels. The initial liquid-water saturation and all surface coverages are uniformly equal to zero at the initial time.

\subsection{Numerical details and parameters}

The initial-boundary value problem developed above was solved in the software package COMSOL Multiphysics ${ }^{\circledR}$ on a uniform grid (typically 128 points) using quartic Lagrange polynomials as trial and test functions. The relative tolerance was set to a value of $1 \times 10^{-6}$ and the absolute tolerance to $1 \times 10^{-8}$. The switch functions were substituted with hyperbolic tangent functions to smooth the discontinuities.

The default set of parameter values is given in Tables 4-10 . Several parameters are estimated, as indicated in Tables 4-10, and the rest are found from the literature with references provided. Where

\section{Table 6}

The default parameter values relating to electrochemical properties

\begin{tabular}{|c|c|c|}
\hline Symbol & Quantity & Size \\
\hline$j_{\mathrm{O}_{2}, \text { ref }}$ & $\begin{array}{l}\text { Cathode exchange current } \\
\text { density [22] }\end{array}$ & $10^{-2} \mathrm{~A} \mathrm{~m}^{-2}$ \\
\hline$c_{\mathrm{O}_{2} \text {, ref }}$ & Reference $\mathrm{O}_{2}$ concentration ${ }^{\mathrm{a}}$ & $0.05 \mathrm{~mol} \mathrm{~m}^{-3}$ \\
\hline$\alpha_{\mathrm{c}}$ & $\begin{array}{l}\text { Cathodic charge transfer } \\
\text { coefficient }\end{array}$ & 0.55 \\
\hline$\alpha_{\mathrm{a}}$ & Anodic charge transfer coefficient & 0.45 \\
\hline$\alpha_{1}$ & $\begin{array}{l}\text { Charge transfer coefficient for } \\
\text { reaction (R1) }\end{array}$ & 0.5 \\
\hline$\alpha_{4}$ & $\begin{array}{l}\text { Charge transfer coefficient for } \\
\text { reaction }(\mathrm{R} 4)^{\mathrm{a}}\end{array}$ & 0.5 \\
\hline$\alpha_{5}$ & $\begin{array}{l}\text { Charge transfer coefficient for } \\
\text { reaction (R5) }\end{array}$ & 0.5 \\
\hline$\alpha_{7}$ & $\begin{array}{l}\text { Charge transfer coefficient for } \\
\text { reaction }(R 7)^{\mathrm{a}}\end{array}$ & 0.5 \\
\hline$i$ & Interaction parameter ${ }^{\mathrm{a}}$ & $10 \mathrm{~kJ} \mathrm{~mol}^{-1}$ \\
\hline$\tau$ & $\begin{array}{l}\text { Molar area density of platinum } \\
\text { sites [7] }\end{array}$ & $0.01042 \mathrm{~mol} \mathrm{~m}^{-2}$ \\
\hline$r_{1 f}$ & $\begin{array}{l}\text { Forward rate constant: reaction } \\
(\mathrm{R} 1)^{\mathrm{b}}\end{array}$ & $3 \times 10^{-2} \mathrm{~ms}^{-1}$ \\
\hline$r_{1 b} / r_{1 f}$ & $\begin{array}{l}\text { Backward rate constant: reaction } \\
(\mathrm{R} 1)^{\mathrm{a}}\end{array}$ & $1.4 \times 10^{-6}$ \\
\hline$r_{2 f}$ & $\begin{array}{l}\text { Forward rate constant: reaction } \\
(\mathrm{R} 2)^{\mathrm{b}}\end{array}$ & $1 \times 10^{-2} \mathrm{~m} \mathrm{~s}^{-1}$ \\
\hline$r_{2 b} / r_{2 f}$ & $\begin{array}{l}\text { Backward rate constant: reaction } \\
(\mathrm{R} 2)^{\mathrm{a}}\end{array}$ & $1 \times 10^{-6} \mathrm{~m}^{3 / 2} \mathrm{~mol}^{-1 / 2}$ \\
\hline$r_{3 f}$ & $\begin{array}{l}\text { Forward rate constant: reaction } \\
\text { (R3) [44] }\end{array}$ & $3 \mathrm{e}^{-10400 / R T} \mathrm{~m} \mathrm{~s}^{-1}$ \\
\hline$r_{3 b} / r_{3 f}$ & $\begin{array}{l}\text { Backward rate constant: reaction } \\
\text { (R3) [44] }\end{array}$ & $4.18 \times 10^{11} \mathrm{e}^{-87900 / R T} \mathrm{~mol} \mathrm{~m}^{-3}$ \\
\hline$r_{4 f}$ & $\begin{array}{l}\text { Forward rate constant: reaction } \\
\text { (R4) [44] }\end{array}$ & $23.1 \mathrm{e}^{-16700 / R T} \mathrm{~mol} \mathrm{~m}^{-2} \mathrm{~s}^{-1}$ \\
\hline$r_{5 f}$ & $\begin{array}{l}\text { Forward rate constant: reaction } \\
(\mathrm{R} 5)^{\mathrm{a}}\end{array}$ & $1 \times 10^{-4} \mathrm{~ms}^{-1}$ \\
\hline$r_{7 f}$ & $\begin{array}{l}\text { Forward rate constant: reaction } \\
(\mathrm{R} 7)^{\mathrm{b}}\end{array}$ & $4 \times 10^{-12} \mathrm{~m}^{7} \mathrm{~s}^{-1} \mathrm{~mol}^{-2}$ \\
\hline
\end{tabular}

\footnotetext{
a Assumed value.
}

b Fitted value.
Table 7

Parameters for the gas-phase diffusion coefficient in Eq. (3)

\begin{tabular}{lll}
\hline Symbol & Quantity & Size \\
\hline$\sigma_{\mathrm{O}_{2}}$ & $\mathrm{O}_{2}$ collision diameter [29] & $3.433 \AA$ \\
$\sigma_{\mathrm{H}_{2}}$ & $\mathrm{H}_{2}$ collision diameter [29] & $2.915 \AA$ \\
$\sigma_{\mathrm{vapour}}$ & Vapour collision diameter [29] & $2.903 \AA$ \\
$\sigma_{\mathrm{N}_{2}}$ & $\mathrm{~N}_{2}$ collision diameter [29] & $3.667 \AA$ \\
$\sigma_{\mathrm{H}_{2} \mathrm{~S}}$ & $\mathrm{H}_{2} \mathrm{~S}$ collision diameter [29] & $3.748 \AA$ \\
$\sigma_{\mathrm{SO}_{3}}$ & $\mathrm{SO}_{3}$ collision diameter [29] & $4.29 \AA$ \\
$\Omega_{\mathrm{N}_{2}, \mathrm{O}_{2}}$ & $\mathrm{O}_{2}-\mathrm{N}_{2}$ collision integral [29] & 0.966 \\
$\Omega_{\mathrm{N}_{2}, \mathrm{H}_{2}}$ & $\mathrm{H}_{2}-\mathrm{N}_{2}$ collision integral [29] & 0.848 \\
$\Omega_{\mathrm{N}_{2}, \text { vapour }}$ & Vapour-N collision integral [29] & 1.305 \\
$\Omega_{\mathrm{N}_{2}, \mathrm{~N}_{2}}$ & $\mathrm{~N}_{2}-\mathrm{N}_{2}$ collision integral [29] & 0.949 \\
$\Omega_{\mathrm{H}_{2}, \mathrm{~N}_{2} \mathrm{~S}}$ & $\mathrm{H}_{2} \mathrm{~S}-\mathrm{N}_{2}$ collision integral [29] & 1.129 \\
$\Omega_{\mathrm{N}_{2}, \mathrm{SO}}$ & $\mathrm{SO} \mathrm{O}_{3}-\mathrm{N}_{2}$ collision integral [29] & 1.06 \\
$M_{\mathrm{O}_{2}}$ & Molar mass of $\mathrm{O}_{2}$ & $0.0032 \mathrm{~kg} \mathrm{~mol}^{-1}$ \\
$M_{\mathrm{H}_{2}}$ & Molar mass of $\mathrm{H}_{2}$ & $0.0002 \mathrm{~kg} \mathrm{~mol}^{-1}$ \\
$M_{\mathrm{H}_{2} \mathrm{O}}$ & Molar mass of $\mathrm{H}_{2} \mathrm{O}$ & $0.0018 \mathrm{~kg} \mathrm{~mol}^{-1}$ \\
$M_{\mathrm{N}_{2}}$ & Molar mass of $\mathrm{N}_{2}$ & $0.0028 \mathrm{~kg} \mathrm{~mol}^{-1}$ \\
$M_{\mathrm{H}_{2} \mathrm{~S}}$ & Molar mass of $\mathrm{H}_{2} \mathrm{~S}$ & $0.0034 \mathrm{~kg} \mathrm{~mol}^{-1}$ \\
$M_{\mathrm{SO}_{3}}$ & Molar mass of SO & $0.008 \mathrm{~kg} \mathrm{~mol}_{3}^{-1}$ \\
\hline
\end{tabular}

Table 8

Default parameter values related to mass transport

\begin{tabular}{|c|c|c|}
\hline Symbol & Quantity & Size \\
\hline$D_{\mathrm{O}_{2}}^{d}$ & $\begin{array}{l}\mathrm{O}_{2} \text { diffusion coefficient in the } \\
\text { electrolyte }^{\mathrm{a},}[45]\end{array}$ & $3.1 \times 10^{-7} \mathrm{e}^{-2768 / T} \mathrm{~m}^{2} \mathrm{~s}^{-1}$ \\
\hline$D_{\mathrm{H}_{2}}^{d}$ & $\begin{array}{l}\mathrm{H}_{2} \text { diffusion coefficient in the } \\
\text { electrolyte }^{\mathrm{a},}[46]\end{array}$ & $6.92 \times 10^{-9} \mathrm{~m}^{2} \mathrm{~s}^{-1}$ \\
\hline$D_{\mathrm{H}_{2} \mathrm{~S}}^{d}$ & $\begin{array}{l}\mathrm{H}_{2} \mathrm{~S} \text { diffusion coefficient in the } \\
\text { electrolyte }^{\mathrm{a}}\end{array}$ & $4.38 \times 10^{-9} \mathrm{~m}^{2} \mathrm{~s}^{-1}$ \\
\hline$h_{\mathrm{pe}, i}$ & Mass transfer rates ${ }^{\mathrm{b}}$ & $10^{5} \mathrm{~s}^{-1}$ \\
\hline$\kappa_{\mathrm{C}}$ & Absolute permeability of CCL [47] & $10^{-13} \mathrm{~m}^{2}$ \\
\hline$\kappa_{\mathrm{G}}$ & Absolute permeability of GDL [47] & $8.7 \times 10^{-12} \mathrm{~m}^{2}$ \\
\hline$\mu_{1}$ & Liquid water viscosity & $10^{-3} \mathrm{~Pa} \mathrm{~s}$ \\
\hline$\mu$ & Dynamic viscosity: air ${ }^{b}$ & $1.8 \times 10^{-5}$ Pa s \\
\hline$\mu$ & Dynamic viscosity: $\mathrm{H}_{2}{ }^{\text {b }}$ & $8.4 \times 10^{-6} \mathrm{~Pa} \mathrm{~s}$ \\
\hline$\sigma^{\prime}$ & Surface tension [26] & $0.07 \mathrm{~N} \mathrm{~m}^{-1}$ \\
\hline$\sigma_{\mathrm{s}}$ & Electronic conductivity & $500 \mathrm{Sm}^{-1}$ \\
\hline
\end{tabular}

a Approximated by value in/for liquid water at $60^{\circ} \mathrm{C}$.

b Estimated.

available, values for Nafion were used. For several mass transport and transfer parameters, values corresponding to liquid water have been used as estimates. The pore size and porosity values fall within typical ranges for conventional PEMFC [39] and variations would not qualitative affect the results in this work.

The kinetic parameters were taken from the literature where available. In the absence of primary experimental data, the

Table 9

Default parameter values related to mass transfer

\begin{tabular}{lll}
\hline Symbol & Quantity & Size \\
\hline$H_{\mathrm{O}_{2}}$ & $\mathrm{O}_{2}$ Henry's law constant [48] & 0.15 \\
$H_{\mathrm{H}_{2}}$ & $\mathrm{H}_{2}$ Henry's law constant [49] & 0.63 \\
$H_{\mathrm{H}_{2} \mathrm{~S}}$ & $\mathrm{H}_{2} \mathrm{~S}$ Henry's law constant & 0.32 \\
$H_{\mathrm{SO}_{3}}$ & $\mathrm{SO}_{3}$ Henry's law constant & 1.94 \\
$h_{\mathrm{des}, 1}$ & Desorption coefficient of dissolved to & 100 \\
& liquid water \\
$h_{\mathrm{ads}, 1}$ & Adsorption coefficient of liquid to & 10 \\
& dissolved water \\
$h_{\mathrm{ads}, v}$ & Absorption coefficient of vapour to & $1 \times 10^{-6} \mathrm{~m} \mathrm{~s}^{-1}$ \\
& dissolved water [34] & \\
$h_{\mathrm{des}, v}$ & Desorption coefficient of dissolved & $3.3 \times 10^{-6} \mathrm{~m} \mathrm{~s}^{-1}$ \\
& water to vapour [34] & $100 \mathrm{~s}^{-1} \mathrm{~atm}^{-1}$ \\
$h_{\mathrm{evap}}$ & Evaporation coefficient [25] & $100 \mathrm{~s}^{-1}$ \\
$h_{\text {cond }}$ & Condensation coefficient [25] & 16.8 \\
$\lambda_{1}^{*}$ & Liquid-equilibrated water content [25] & \\
\hline a Assumed value.
\end{tabular}


Table 10

Default parameter values for the heat equation

\begin{tabular}{lll}
\hline Symbol & Quantity & Size \\
\hline$k$ & Catalyst layer thermal conductivity [50] & $0.67 \mathrm{~W} \mathrm{~m}^{-1} \mathrm{~K}^{-1}$ \\
$k_{\mathrm{m}}$ & Membrane thermal conductivity [50] & $0.67 \mathrm{~W} \mathrm{~m}^{-1} \mathrm{~K}^{-1}$ \\
$k_{\mathrm{G}}$ & GDL thermal conductivity [50] & $1.67 \mathrm{~W} \mathrm{~m}^{-1} \mathrm{~K}^{-1}$ \\
$\rho_{\mathrm{l}} C_{\mathrm{l}}$ & $\mathrm{H}_{2} \mathrm{O}$ thermal capacitance & $4.187 \times 10^{6} \mathrm{~J} \mathrm{~m}^{-3} \mathrm{~K}^{-1}$ \\
$\rho_{\mathrm{g}} C_{\mathrm{g}}$ & Gas phase thermal capacitance/air & $10^{3} \mathrm{~J} \mathrm{~m}^{-3} \mathrm{~K}^{-1}$ \\
$\rho_{\mathrm{m}} C_{\mathrm{m}}$ & Membrane thermal capacitance & $2.18 \times 10^{6} \mathrm{~J} \mathrm{~m}^{-3} \mathrm{~K}^{-1}$ \\
$\rho_{\text {carb }} C_{\text {carb }}$ & Carbon phase thermal capacitance & $1.61 \times 10^{6} \mathrm{~J} \mathrm{~m}^{-3} \mathrm{~K}^{-1}$ \\
$-\Delta s_{\mathrm{c}}$ & Entropy associated with ORR [51] & $163.7 \mathrm{~J} \mathrm{~mol}^{-1} \mathrm{~K}^{-1}$ \\
$-\Delta s_{\mathrm{a}}$ & Entropy associated with HOR [51] & $0 \mathrm{~J} \mathrm{~mol}^{-1} \mathrm{~K}^{-1}$ \\
\hline
\end{tabular}

a Estimated.

values for $r_{1 b} / r_{1 f}, r_{2 b} / r_{2 f}$ and $r_{5 f}$ were assigned arbitrarily and the values for $r_{1 f}, r_{2 f}$ and $r_{7 f}$ were fitted to the provided a qualitative match to the values and trends in [1,16]. As confirmation of the values, the fitted adsorption rate constant $r_{1 f}$ was compared to that approximated from experimental data at different temperatures by Mohtadi et al. in [1]. Their predicted value is of the same order of magnitude, $O\left(10^{-2}\right)$, as that shown in Table 6 .

In the next section use will be made of the spatially averaged reaction rates and surface coverages. These are defined as the integrals of the reaction rates or surface coverages in space over the
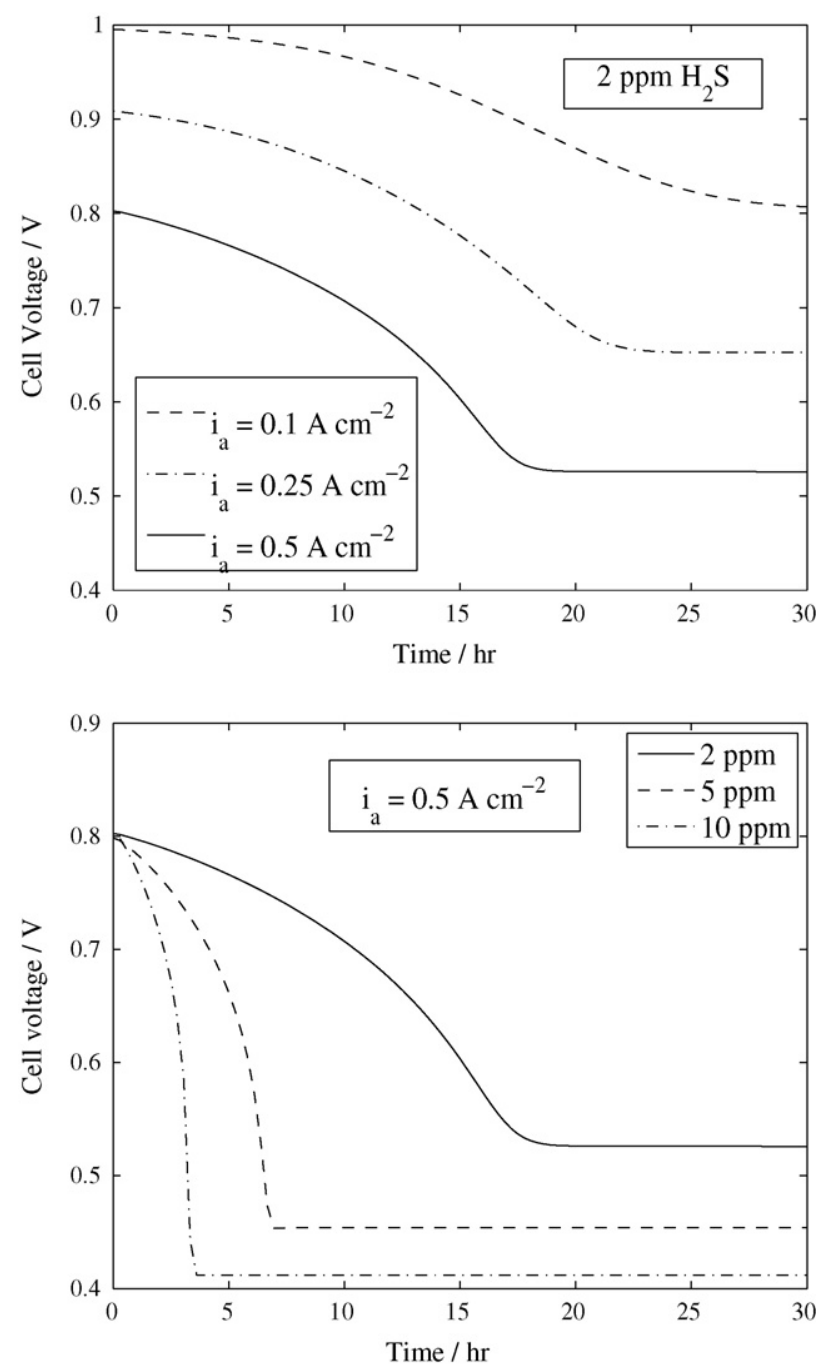

Fig. 2. The effect of $\mathrm{H}_{2} \mathrm{~S}$ concentration and current density on the extent of poisoning when operating in galvanostatic mode. See Tables 4-10 for values of the other parameters. anode catalyst layer, normalised with respect to $L$, the length of the catalyst layer:

$$
\begin{aligned}
\left\langle q_{i}\right\rangle & =\frac{1}{L} \int_{\mathrm{ACL}} q_{i} \mathrm{~d} y \\
\left\langle\theta_{\mathrm{S}}\right\rangle & =\frac{1}{L} \int_{\mathrm{ACL}} \theta_{\mathrm{S}} \mathrm{d} y \\
\left\langle\theta_{\mathrm{H}}\right\rangle & =\frac{1}{L} \int_{\mathrm{ACL}} \theta_{\mathrm{H}} \mathrm{d} y .
\end{aligned}
$$

The terminal value of a quantity $\psi(t)$ will be defined as the value of $\psi$ at steady state, i.e.:

"Terminal value of $\psi(t) "=\psi(\infty)$.

\section{Results and discussion}

\subsection{Basic features and validation}

Fig. 2 shows simulation results at different current densities, at a fixed $\mathrm{H}_{2} \mathrm{~S}$ concentration of $2 \mathrm{ppm}$, and different $\mathrm{H}_{2} \mathrm{~S}$ concentrations, at a fixed current density of $0.5 \mathrm{~A} \mathrm{~cm}^{-2}$. The simulations are of
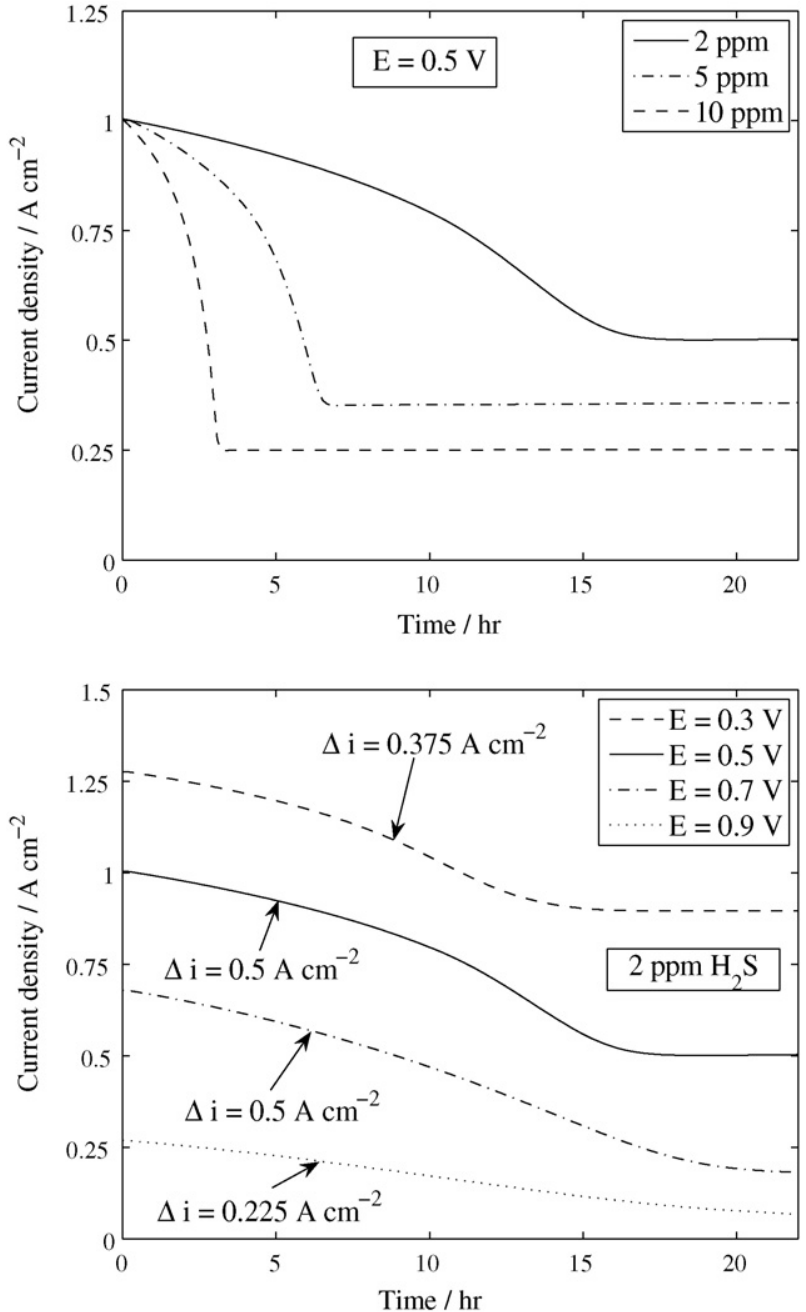

Fig. 3. The effect of $\mathrm{H}_{2} \mathrm{~S}$ concentration (top figure) and cell voltage (bottom) on the extent of performance loss when operating in potentiostatic mode. In the top figure the cell voltage is fixed at $0.5 \mathrm{~V}$ and in the bottom figure the $\mathrm{H}_{2} \mathrm{~S}$ concentration is fixed at $2 \mathrm{ppm}$. The temperature is $60^{\circ} \mathrm{C}$ in both figures. See Tables $4-10$ for values of the other parameters. 
operation in the galvanostatic mode. The hydrogen source in these simulations is $40 \% \mathrm{H}_{2}$ in $\mathrm{N}_{2}$. The other parameter values are given in Tables 4-10 and are used throughout, unless otherwise stated. These tables also contain the default values of current density, voltage and $\mathrm{H}_{2} \mathrm{~S}$ concentration. In each simulation the initial conditions were generated from a gradual increase in the current over a period of $500 \mathrm{~s}$ from $0 \mathrm{~A} \mathrm{~cm}^{-2}$, and $0 \mathrm{ppm} \mathrm{H}_{2} \mathrm{~S}$, to the stated current den-
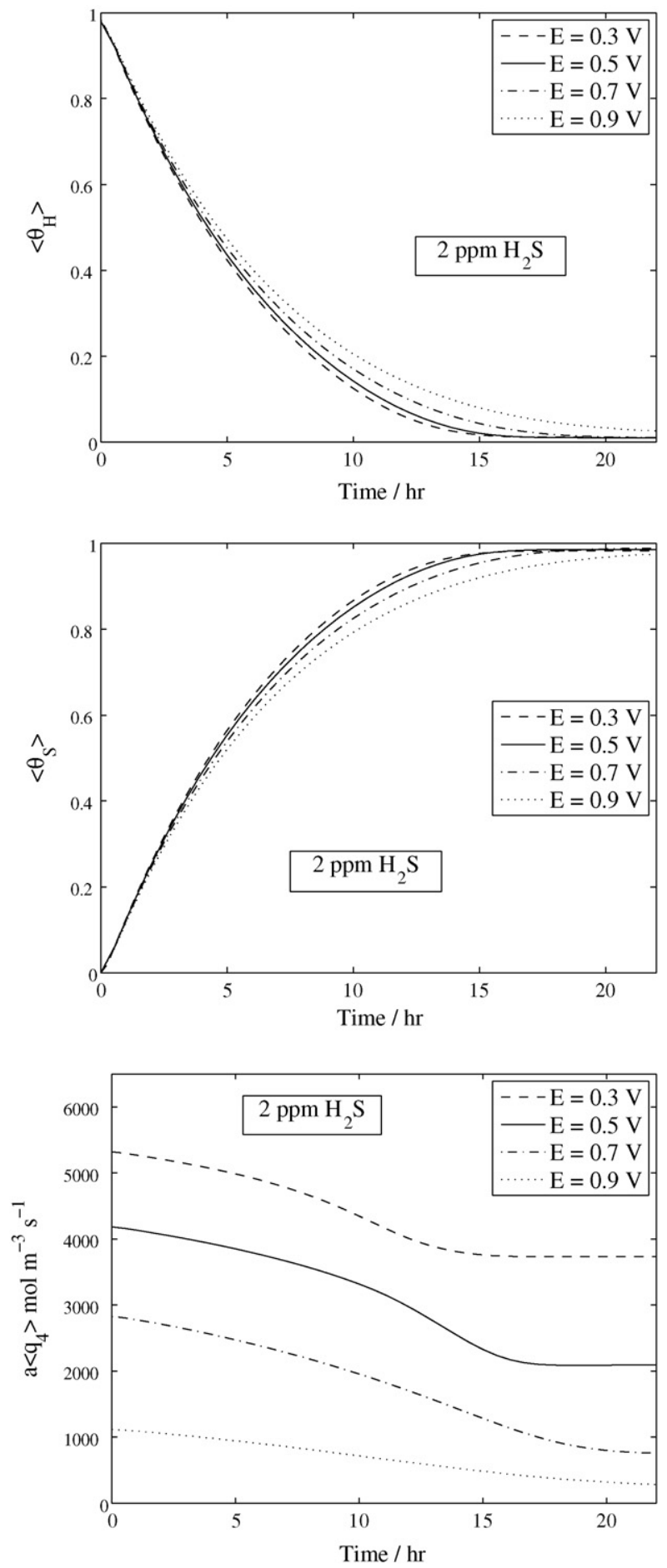

Fig. 4. The evolutions of the average values of the hydrogen oxidation rate, $q_{4}$, and the surface coverages of sulfur and hydrogen, $a\left\langle q_{4}\right\rangle,\left\langle\theta_{\mathrm{S}}\right\rangle$ and $\left\langle\theta_{\mathrm{H}}\right\rangle$, respectively, at different cell voltage values with an $\mathrm{H}_{2} \mathrm{~S}$ concentration of $2 \mathrm{ppm}$ and at a temperature of $60^{\circ} \mathrm{C}$. See Tables $4-10$ for values of the other parameter. Table 11 shows the terminal values of $\left\langle\theta_{\mathrm{S}}\right\rangle$ and $\left\langle\theta_{\mathrm{H}}\right\rangle$.
Table 11

Terminal values of the spatially averaged surface coverages of hydrogen and sulfur $\left\langle\theta_{\mathrm{H}}\right\rangle$ and $\left\langle\theta_{\mathrm{S}}\right\rangle$ respectively, corresponding to the calculations in Figs. 3 and 4

\begin{tabular}{lll}
\hline Cell voltage $(\mathrm{V})$ & Terminal $\left\langle\theta_{\mathrm{S}}\right\rangle$ & Terminal $\left\langle\theta_{\mathrm{H}}\right\rangle$ \\
\hline 0.3 & 0.9826 & 0.01085 \\
0.5 & 0.9862 & 0.00987 \\
0.7 & 0.9895 & 0.00975 \\
0.9 & 0.9830 & 0.01082 \\
\hline
\end{tabular}

The $\mathrm{H}_{2} \mathrm{~S}$ concentration is $2 \mathrm{ppm}$ and the channel temperatures are $60^{\circ} \mathrm{C}$. See Tables 4-10 for values of the other parameters.

sity value, followed by $2 \mathrm{~h}$ at this current density. A steady state was reached in each case.

In both cases, the results in Fig. 2 results capture precisely the trends observed in the experiments of Shi et al. [16]. As the current density is increased at fixed $\mathrm{H}_{2} \mathrm{~S}$ concentration the extent of poisoning (decrease in cell voltage) increases. As the $\mathrm{H}_{2} \mathrm{~S}$ concentration is increased at a fixed current density the degree of poisoning again increases.

Fig. 3 shows simulation results in the potentiostatic mode at different values of $\mathrm{H}_{2} \mathrm{~S}$ concentration and cell voltage, again with $40 \% \mathrm{H}_{2}$ in $\mathrm{N}_{2}$. In these simulations the initial conditions were generated from a gradual increase in the cell voltage over a period of

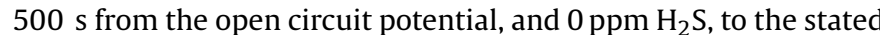
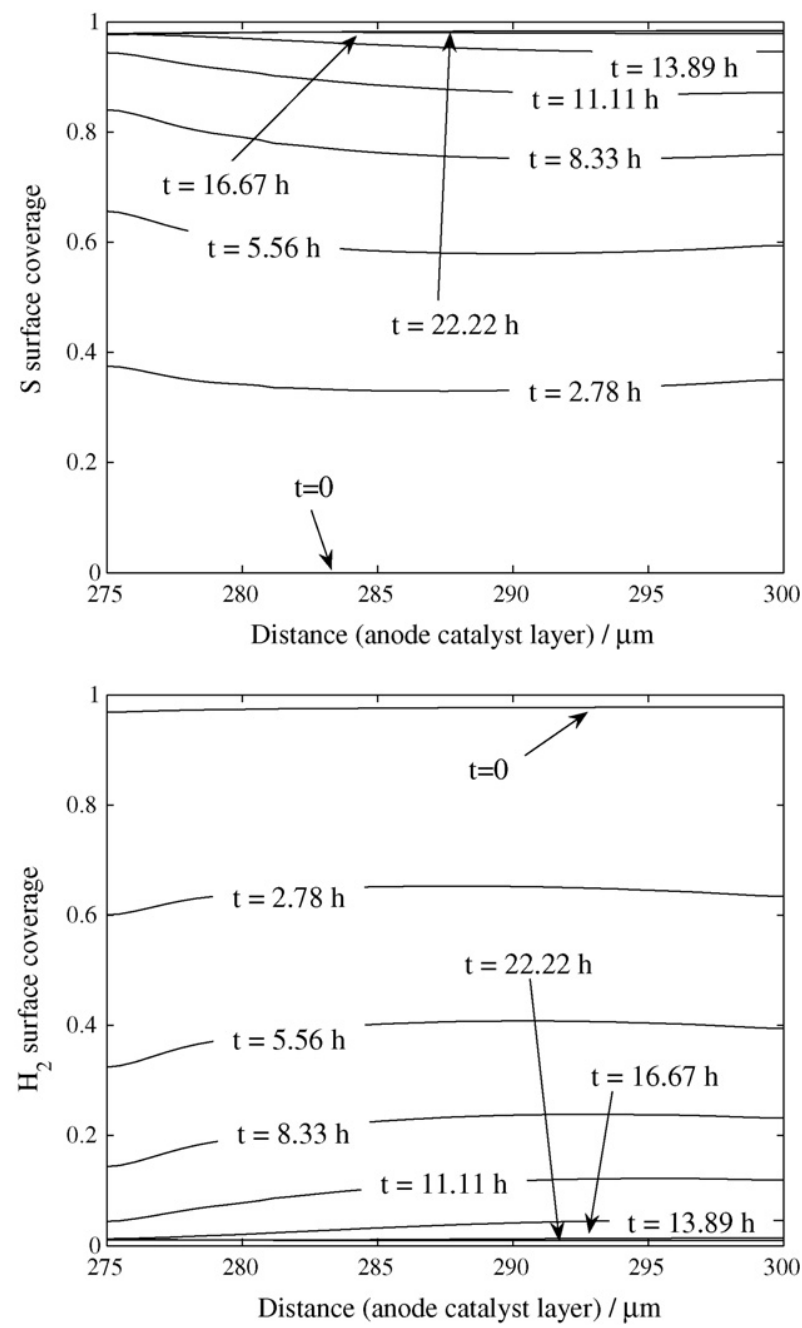

Fig. 5. The evolutions of the profiles of sulfur and hydrogen surface coverages during poisoning, corresponding to the calculation at a cell voltage of $0.5 \mathrm{~V}$ with $2 \mathrm{ppm} \mathrm{H}_{2} \mathrm{~S}$ in Fig. 3. See Tables 4-10 for values of the other parameters. 
cell voltage value, followed by operation at this cell voltage until a steady state was reached.

As the $\mathrm{H}_{2} \mathrm{~S}$ concentration is increased at a fixed cell voltage of $0.5 \mathrm{~V}$, the drop in current density as a result of poisoning increases. The profiles are a good fit to the transient data in $[1,18]$ showing the decay of the anode current density. The trend with respect to variations in cell voltage at a fixed $\mathrm{H}_{2} \mathrm{~S}$ concentration indicates that the degree of poisoning initially increases as the cell voltage is decreased, but as the cell voltage is lowered further, performance improves; that is seen by comparing the current density changes from the initial time to steady state, $\Delta i$, shown in Fig. 3 . This result is caused by the trend in the rate of hydrogen oxidation from the platinum surfaces, reaction (R4), as the cell voltage is lowered. Fig. 4 shows the evolutions of the spatially averaged hydrogen oxidation rate, $a\left\langle q_{4}\right\rangle$, the spatially averaged surface coverage of sulfur, $\left\langle\theta_{\mathrm{S}}\right\rangle$, and the spatially averaged surface coverage of hydrogen, $\left\langle\theta_{\mathrm{H}}\right\rangle$. In these figures the cell voltage is varied from 0.9 to $0.3 \mathrm{~V}$ with $2 \mathrm{ppm}$ $\mathrm{H}_{2} \mathrm{~S}$ at an operating temperature of $60^{\circ} \mathrm{C}$, as in Fig. 3 .

The variation in current density in Fig. 3 as the cell voltage is lowered mirrors the variation in $a\left\langle q_{4}\right\rangle$, clearly demonstrating that the oxidation of hydrogen controls the extent of degradation. The terminal values of $\left\langle\theta_{\mathrm{S}}\right\rangle$ and $\left\langle\theta_{\mathrm{H}}\right\rangle$, defined in Eq. (41), are shown in Table 11 . The terminal value of $\left\langle\theta_{\mathrm{H}}\right\rangle$ decreases as the cell voltage is increased from 0.3 to $0.5 \mathrm{~V}$ and again from 0.5 to $0.7 \mathrm{~V}$. On the other hand, the terminal value of $\left\langle\theta_{\mathrm{H}}\right\rangle$ increases as the cell voltage is increased from 0.7 to $0.9 \mathrm{~V}$. Correspondingly, the terminal value of $\left\langle\theta_{\mathrm{S}}\right\rangle$ increases from 0.3 to $0.7 \mathrm{~V}$ and decreases from 0.7 to $0.9 \mathrm{~V}$. This would suggest that as the cell voltage is lowered the extent of degradation, measured by the drop in current density, reaches a maximum, which is indeed the case in Fig. 3.

Fig. 5 shows the evolution of the surface coverage profiles during the calculation at $0.5 \mathrm{~V}$ with $2 \mathrm{ppm}_{2} \mathrm{~S}$. At the initial time, when the concentration of $\mathrm{H}_{2} \mathrm{~S}$ is increased from 0 to $2 \mathrm{ppm}$, the coverage of platinum sites by hydrogen is almost complete. Within $2.78 \mathrm{~h}$ roughly $40 \%$ of the surface area is covered by sulfur, with a corresponding decrease in adsorbed hydrogen. Thereafter, the adsorption rate of sulfur is increasingly slower but at the terminal current density the surface coverage of sulfur is close to a monolayer: $\theta_{\mathrm{S}} \approx 1$.

\subsection{Effect of channel temperature and water activity}

The effect of temperature on the extent of poisoning is depicted in Fig. 6, showing simulation results at different channel tempera-

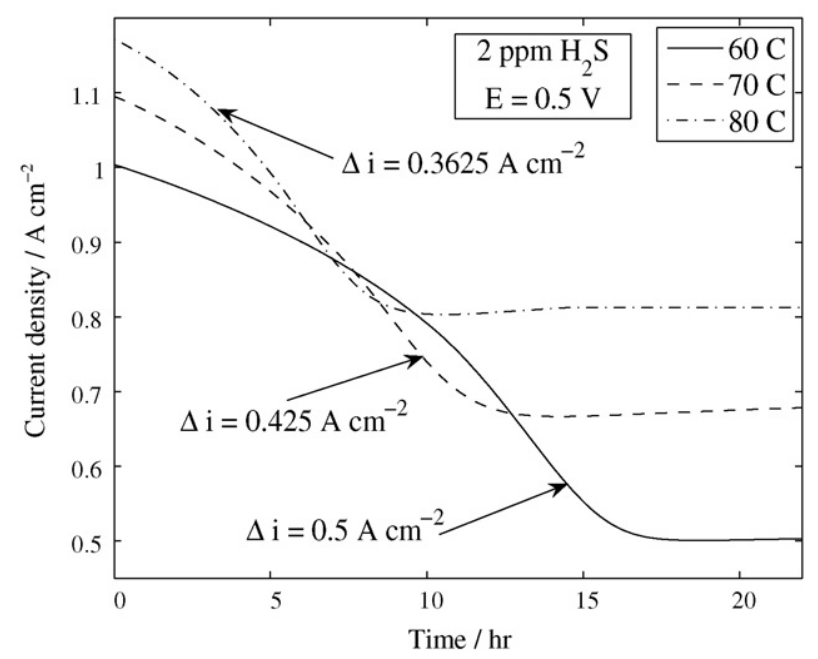

Fig. 6. The effect of channel temperature on $\mathrm{H}_{2} \mathrm{~S}$ poisoning: for an $\mathrm{H}_{2} \mathrm{~S}$ concentration of $2 \mathrm{ppm}$ and a cell voltage of $0.5 \mathrm{~V}$. See Tables $4-10$ for values of the other parameters.
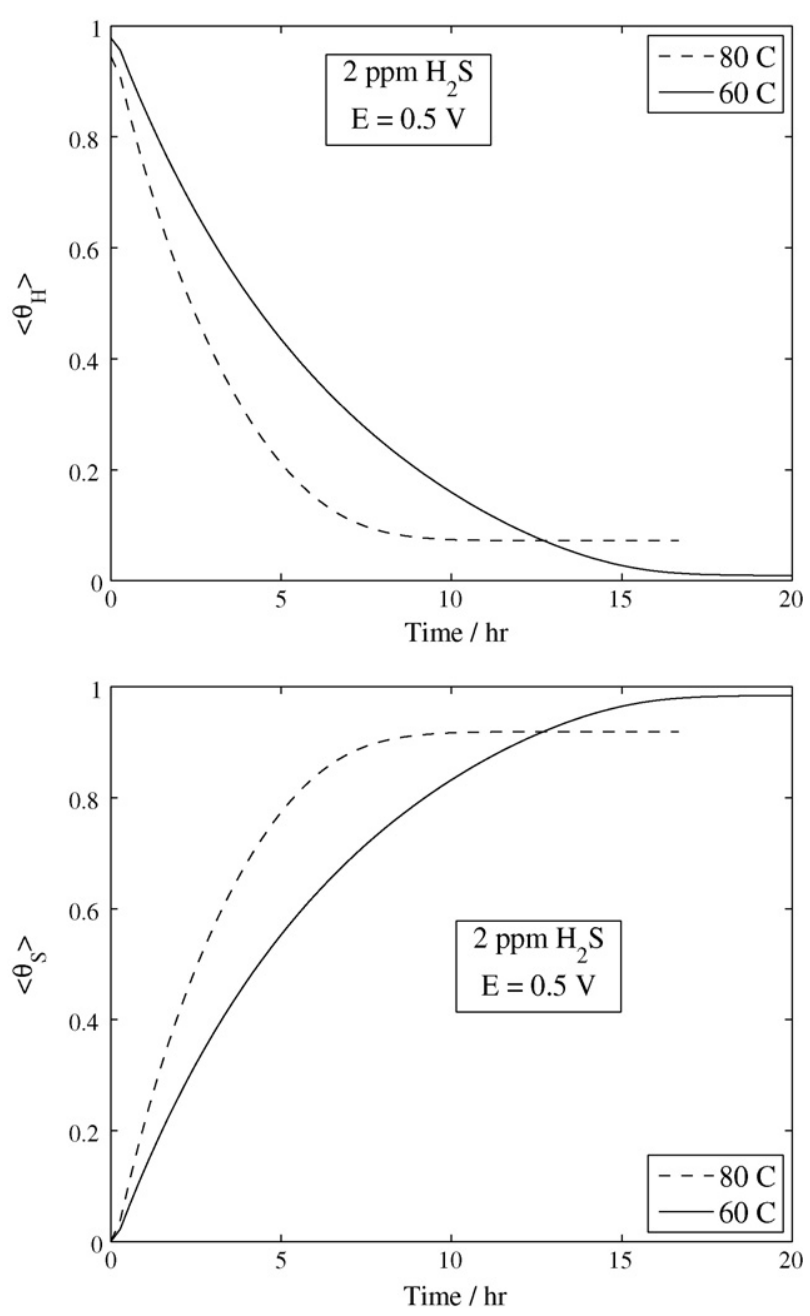

Fig. 7. The evolution of the spatially averaged surface coverages of sulfur and hydrogen, $\left\langle\theta_{\mathrm{S}}\right\rangle$ and $\left\langle\theta_{\mathrm{H}}\right\rangle$, respectively, corresponding to the calculations at channel temperatures of 60 and $80^{\circ} \mathrm{C}$ shown in Fig. 6. See Tables $4-10$ for values of the other parameters.

tures for an $\mathrm{H}_{2} \mathrm{~S}$ concentration of $2 \mathrm{ppm}$ and a cell voltage of $0.5 \mathrm{~V}$. It is immediately noticeable that the initial current density increases as the channel temperature is increased. There are several effects associated with a temperature increase at fixed values of other quantities in the absence of $\mathrm{H}_{2} \mathrm{~S}$ : a decrease in the channel concentration of reactants; a decrease in the reaction rates for oxygen reduction and hydrogen oxidation through the Arrhenius dependence; a decrease in the rate of condensation through an increase in the saturation vapour pressure and a reduction in the channel vapour concentration; and an increase in the membrane conductivity. The latter effect dominates, leading to the higher initial current density.

As the channel temperature is increased the drop in current density from its initial to terminal value decreases, leading to a reduced degree of poisoning. This can bee seen from the current density changes, $\Delta i$, shown in Fig. 6 at each temperature. Fig. 7 shows the evolution of the spatially averaged surface coverages of sulfur and hydrogen defined in Eq. (40), corresponding to the calculations at 60 and $80^{\circ} \mathrm{C}$ in Fig. 6 . These plots demonstrate that the reduced degree of poisoning is the result of a greater terminal coverage of hydrogen and a lower terminal coverage of sulfur at the higher temperature. 
However, Fig. 7 also shows that the coverage of platinum sites by sulfur is more rapid as the temperature is increased, so that $\theta_{\mathrm{S}}$ is higher and $\theta_{\mathrm{H}}$ is lower up to approximately $t=13 \mathrm{~h}$, at which point the curves intersect. Thus, although poisoning is less severe at the higher temperature on a long time scale, the rate of poisoning is faster, i.e., the current density drops more rapidly. Indeed the two curves at 60 and $80^{\circ} \mathrm{C}$ in Fig. 6 intersect at approximately $t=7 \mathrm{~h}$.

The above result agrees with the experimental data of Mohtadi et al. [1], in which the authors estimate the surface coverage of sulfur at different temperatures by dividing the oxidation charge by the maximum total charge obtained under sulfur saturation conditions. More precisely, the shape of the profiles of $\left\langle\theta_{\mathrm{S}}\right\rangle$ and the trend with respect to temperature in Fig. 7, before a steady state is established, match the shape and trend in Fig. 4 of [1]. The timescales are also very similar. Mohtadi et al. do however estimate that the surface coverage of sulfur at long times increases with temperature, which seems not to support the crossing of the curves in Fig. 7. The authors also state that the half-cell current decrease at $90^{\circ} \mathrm{C}$ was lower than the current decrease corresponding to the same sulfur coverage for full cells at 70 and $50^{\circ} \mathrm{C}$. Therefore they chose not to base the coverage calculations on the current decrease. They hypothesise that sulfur crosses over to the cathode, thus affecting the oxygen reduction reaction. Furthermore, the full-cell curves at 50 and $70^{\circ}$ C in Fig. 7 of their paper were found to cross at intermediate times before a steady state was established, in a manner similar to that in Fig. 6. The results are therefore inconclusive. Certain elements of the results displayed in Figs. 6 and 7 can be validated, but the behaviour seen as the steady states are approached cannot be confirmed until further data is available. On the other hand several of the results in [1] seem to support it. The following hypothesis, to be discussed below, is made: the nonlinear behaviour found in
[1] is due to the competition between adsorption and oxidation of sulfur.

To investigate the behaviour described above the reader is referred to Fig. 8, which shows the corresponding evolutions at both temperatures of the spatially averaged rates of the surface reactions (R1), (R3), (R4) and (R7), defined in Eq. (40): $a\left\langle q_{1}\right\rangle, a\left\langle q_{3}\right\rangle$, $a\left\langle q_{4}\right\rangle$ and $a\left\langle q_{7}\right\rangle$. These are sulfur adsorption, hydrogen adsorption, hydrogen oxidation and sulfur oxidation respectively. In both cases the average rate of sulfur adsorption, $a\left\langle q_{1}\right\rangle$, rises rapidly as the fuel source is changed from clean to contaminated. The terminal value of $a\left\langle q_{1}\right\rangle$ increases as the temperature is increased, and $a\left\langle q_{1}\right\rangle$ relaxes to a steady-state value in a shorter period of time. At fixed $\theta_{\mathrm{S}}$ and $\theta_{\mathrm{Pt}}$, the forward part of the reaction rate $q_{1}$ in Eq. (29) increases and the backward part decreases as temperature is increased. The result is a higher value of $\theta_{S}$ at $80^{\circ} \mathrm{C}$ during the early stages of its evolution (before steady state). This occurs in competition with the increased adsorption rate of hydrogen shown in Fig. 8. As $\theta_{\mathrm{S}}$ increases the sulfur adsorption rate decreases (a consequence of the Frumkin kinetics), and thus a steady state is reached sooner. On the other hand, the average oxidation rate of sulfur, $a\left\langle q_{7}\right\rangle$, is greater at the higher temperature. The relative increase in the terminal value of $a\left\langle q_{7}\right\rangle$, that is

terminal value at $80^{\circ} \mathrm{C}$ - terminal value at $60^{\circ} \mathrm{C}$ terminal value at $60^{\circ} \mathrm{C}$

is equal to 1.9167 , while the relative increase in the terminal value of $a\left\langle q_{1}\right\rangle$ is 1.727 , which further suggests that the terminal value of $\theta_{\mathrm{S}}$ should be lower at $80^{\circ} \mathrm{C}$. This is indeed the case in Fig. 7. In other words, the increase in the adsorption rate of sulfur at $80^{\circ}$ $\mathrm{C}$ is dominated by the simultaneous increase in its oxidation rate. The equivalent relative increases in $a\left\langle q_{3}\right\rangle$ and $a\left\langle q_{4}\right\rangle$ are almost identical (approximately 0.62 ) implying that the increased adsorption
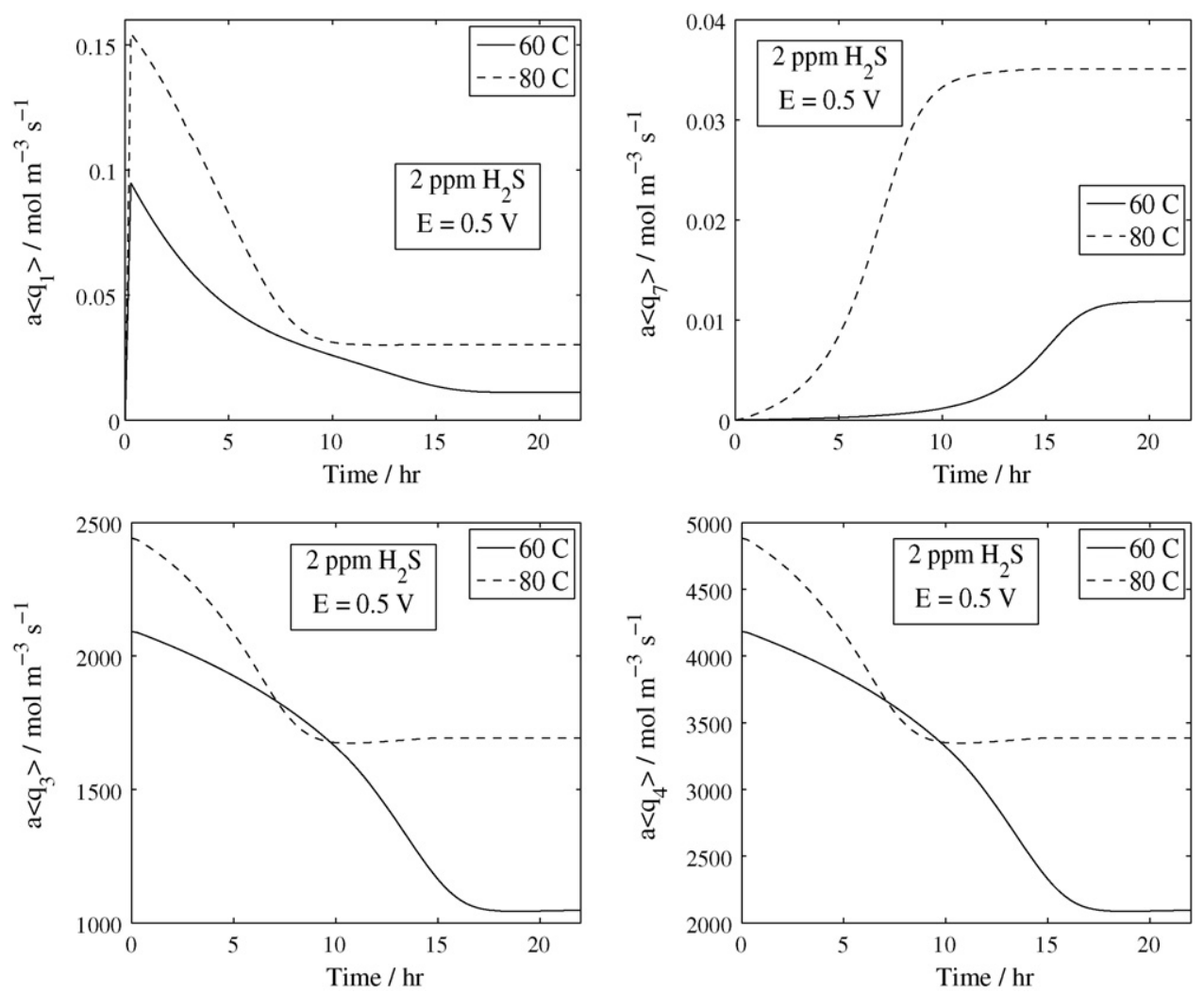

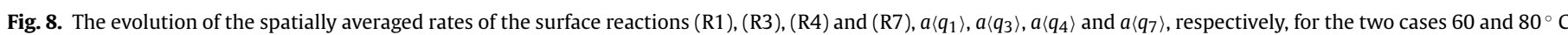
shown in Fig. 6. See Tables 4-10 for values of the other parameters. 

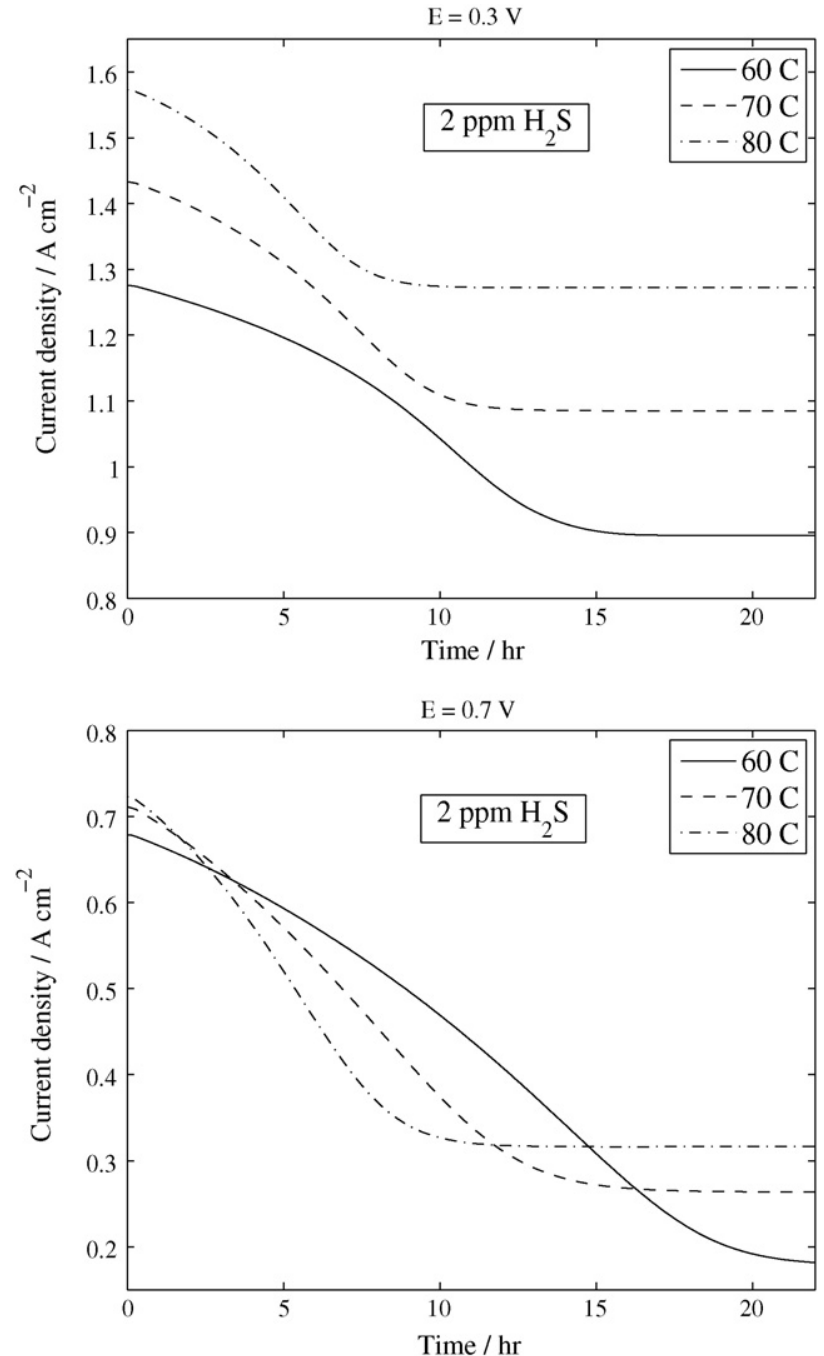

Fig. 9. The effect of simultaneous changes in the channel temperature and cell voltage on $\mathrm{H}_{2} \mathrm{~S}$ poisoning: for an $\mathrm{H}_{2} \mathrm{~S}$ concentration of $2 \mathrm{ppm}$. See Tables 4-10 for values of the other parameters.

of atomic hydrogen is dominated by its increased oxidation. The higher terminal value of $\theta_{\mathrm{H}}$ at $80^{\circ} \mathrm{C}$ is therefore a direct consequence of the lower terminal value of $\theta_{\mathrm{S}}$. Note finally that the reaction rates for sulfur are much smaller than those for hydrogen, which is due to the very small $\mathrm{H}_{2} \mathrm{~S}$ concentrations.

These results pertain to a cell voltage of $0.5 \mathrm{~V}$. To see the effect of changes in the cell voltage as the channel temperature is varied, the reader is referred to Fig. 9. As the cell voltage is increased, the difference in the terminal current density between 60 and $80^{\circ}$ $C$ decreases. For example, at $E=0.3 \mathrm{~V}$ the difference is approximately $0.37 \mathrm{~A} \mathrm{~cm}^{-2}$ and at $E=0.7 \mathrm{~V}$ it is approximately $0.14 \mathrm{~A} \mathrm{~cm}^{-2}$. Moreover, there is a qualitative difference between the two sets of curves in Fig. 9; at $E=0.3 \mathrm{~V}$ performance is uniformly better at higher temperature, whereas at $E=0.7$ the performance at lower temperature is superior except towards the beginning of the calculation and towards the end after the terminal current density has been reached at the higher temperature; performance at $60^{\circ} \mathrm{C}$ is better than performance at $70^{\circ} \mathrm{C}$ between $3.39<t<16.26 \mathrm{~h}$. For both $E=0.3 \mathrm{~V}$ and $E=0.7 \mathrm{~V}$, Fig. 10 shows the evolutions of $a\left\langle q_{1}\right\rangle$ and $a\left\langle q_{7}\right\rangle$ at $80^{\circ} \mathrm{C}$ and Fig. 11 shows the evolutions of $a\left\langle q_{1}\right\rangle$ and $a\left\langle q_{7}\right\rangle$ at $60^{\circ} \mathrm{C}$. At $60^{\circ} \mathrm{C}$, there is a visible delay in the times taken for both $a\left\langle q_{1}\right\rangle$ and $a\left\langle q_{7}\right\rangle$ to relax to their steady-state values. In contrast, the differences in these times at $80^{\circ} \mathrm{C}$ are slight. Thus, while at $80^{\circ} \mathrm{C}$ the rate of poisoning changes little when the cell voltage is decreased from 0.7 to $0.3 \mathrm{~V}$, at $60^{\circ} \mathrm{C}$ it visibly increases. This, allied with the increasing differences in initial current densities as the cell voltage is increased, explains why the curves in Fig. 9 intersect at $0.7 \mathrm{~V}$ but not at $0.3 \mathrm{~V}$.

One of the main performance control mechanisms in PEM fuel cells is the channel water activity, which must be chosen such that the membrane remains well hydrated for sufficiently high protonic conductivity and such that flooding does not occur in the cathode catalyst layer, restricting reactant access to the catalyst sites. Fig. 12 shows the effect of variations in the water activity (the same in both channels) at a cell voltage of $0.5 \mathrm{~V}$ and with $2 \mathrm{ppm} \mathrm{H}_{2} \mathrm{~S}$ in $40 \% \mathrm{H}_{2} / \mathrm{N}_{2}$. All other parameters are fixed as in Tables 4-10. The plots reveal an improvement in performance in going from $a_{\mathrm{w}}=0.7$ (equilibrium relative humidity of $70 \%$ ) to $a_{\mathrm{w}}=1$ in both channels. However, for water activities below 0.7 , very little change in the performance is seen.

It is instructive to examine the water saturation profiles for the two cases of $a_{\mathrm{w}}=1$ and $a_{\mathrm{w}}=0.7$; these are shown in Fig. 13. Immediately noticeable is that the saturation levels in the case $a_{\mathrm{w}}=0.7$ are lower, clearly as a result of the reduced rates of condensation. The levels in the anode are practically zero and are not therefore visible in these plots. The second feature to notice is that the saturation levels fall markedly during the poisoning process. In the cathode the lower current density due to poisoning reduces the
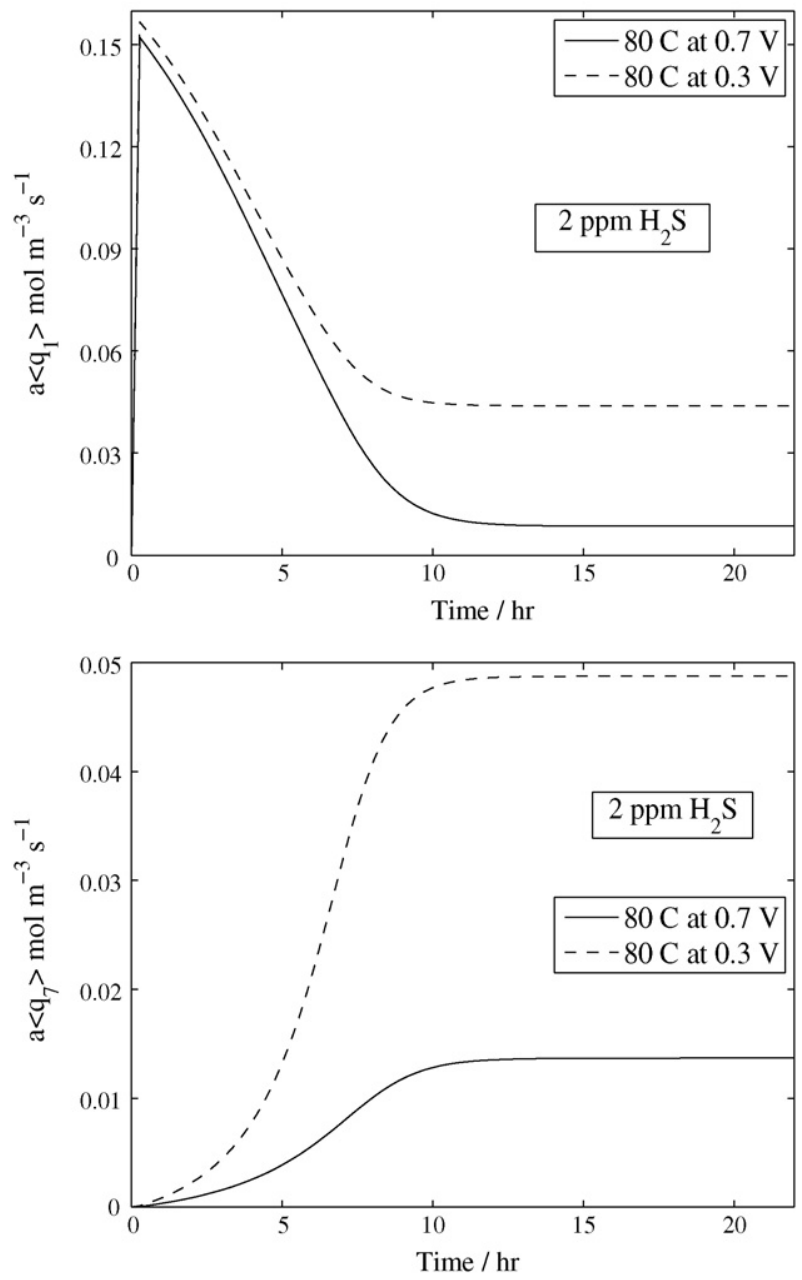

Fig. 10. The evolutions of the spatially averaged rates of the surface reactions (R1) and (R7), $a\left\langle q_{1}\right\rangle$ and $a\left\langle q_{7}\right\rangle$, respectively, for the case $80^{\circ} \mathrm{C}$ shown in Fig. 9. See Tables 4-10 for values of the other parameters. 

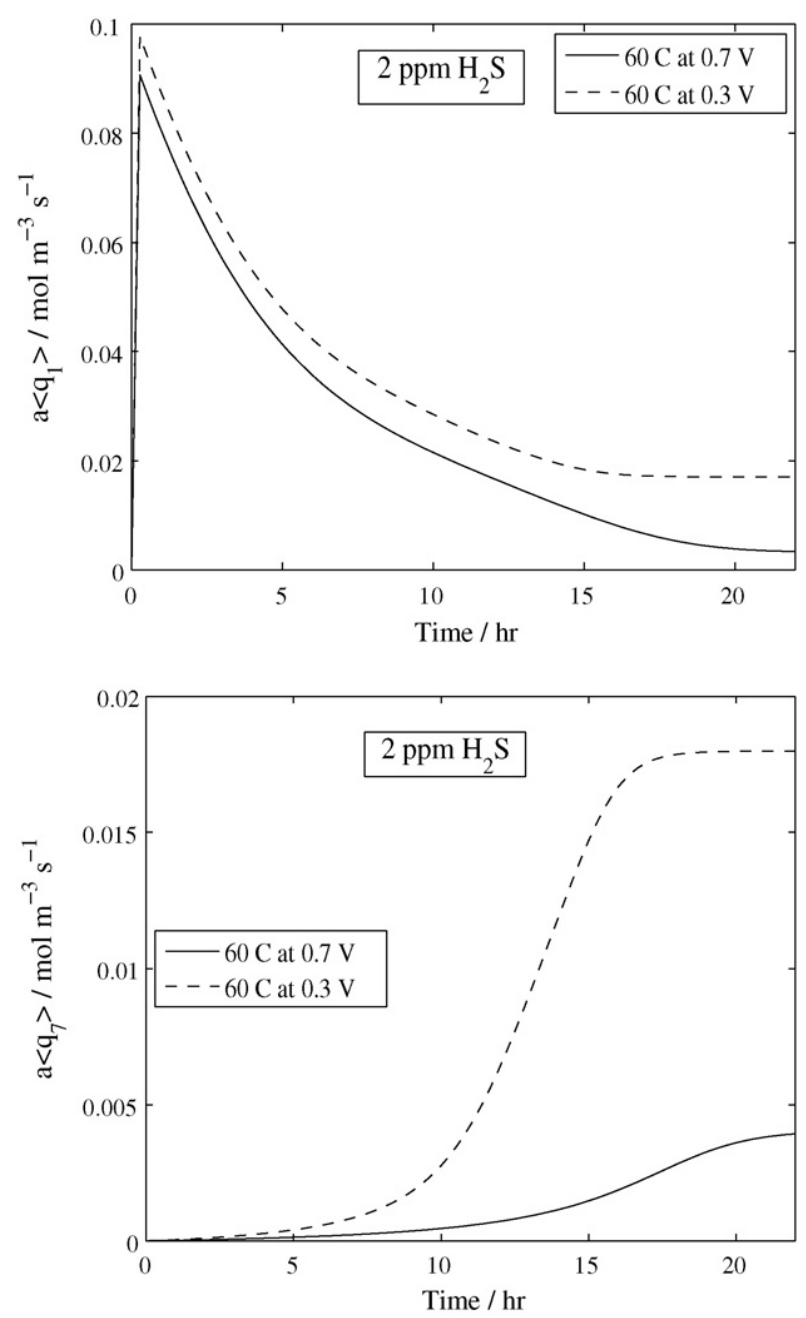

Fig. 11. The evolutions of the spatially averaged rates of the surface reactions (R1) and (R7), $a\left\langle q_{1}\right\rangle$ and $a\left\langle q_{7}\right\rangle$, respectively, for the case $60^{\circ} \mathrm{C}$ and $2 \mathrm{ppm} \mathrm{H}_{2} \mathrm{~S}$. See Tables 4-10 for values of the other parameters.

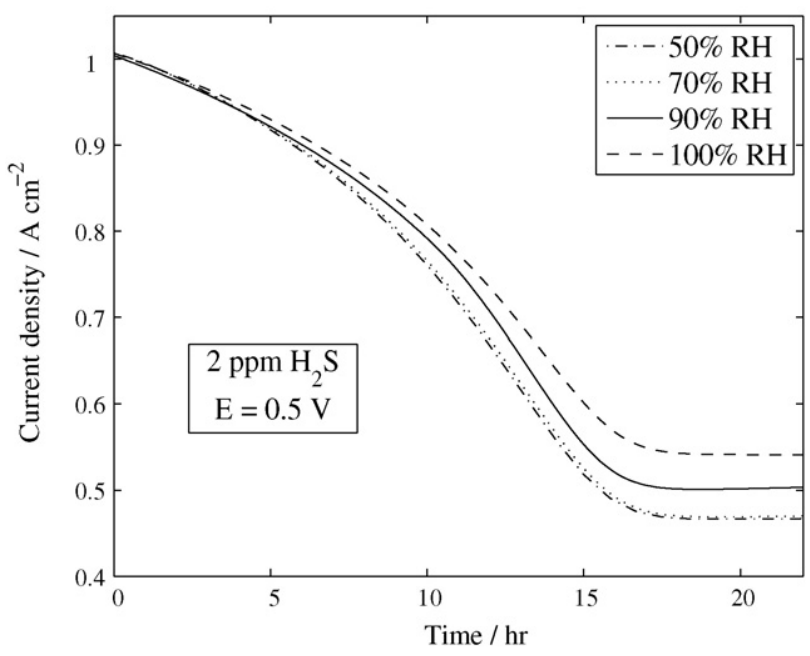

Fig. 12. The effect of channel water activity on $\mathrm{H}_{2} \mathrm{~S}$ poisoning for an $\mathrm{H}_{2} \mathrm{~S}$ concentration of $2 \mathrm{ppm}$ and a cell voltage of $0.5 \mathrm{~V}$. See Tables $4-10$ for values of the other parameters.
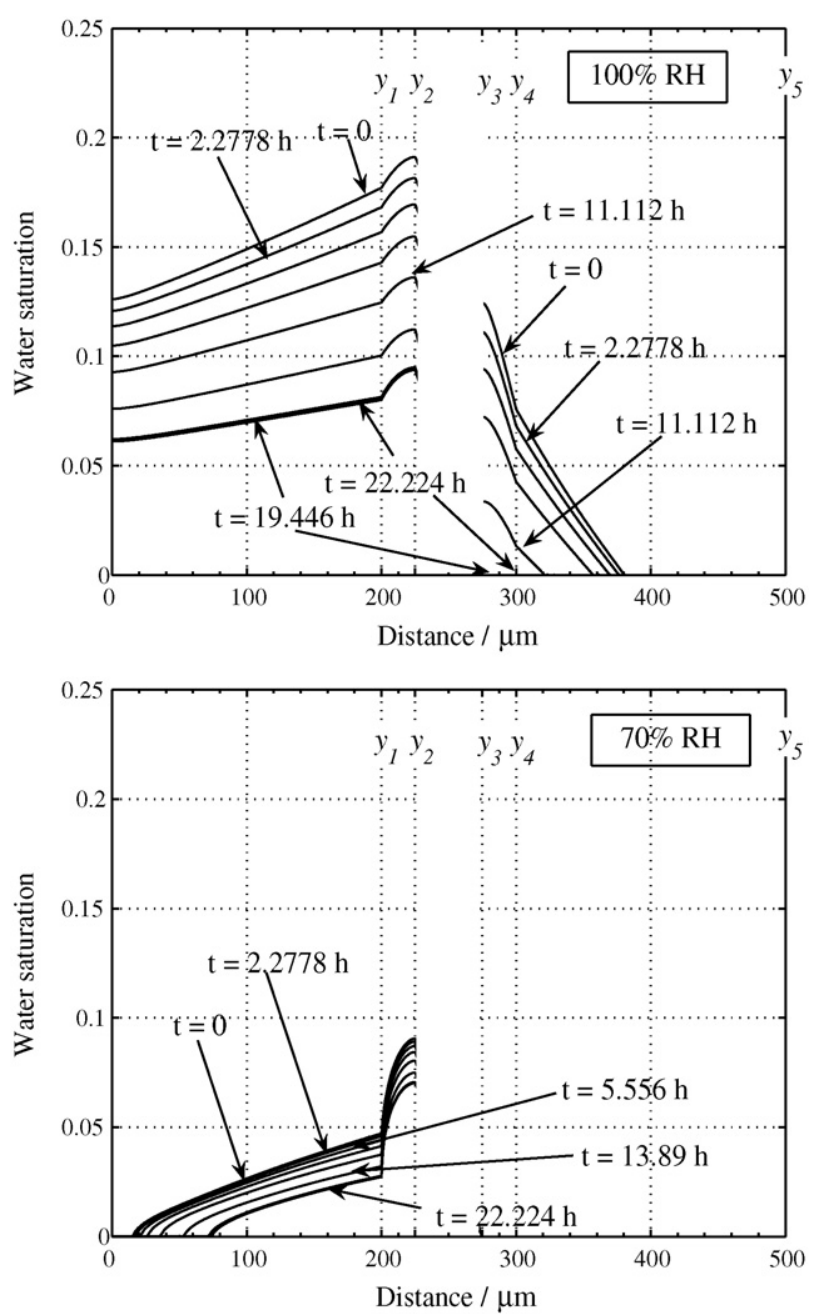

Fig. 13. The evolutions of the water saturation during the calculations at water activities of 1 and 0.7 shown in Fig. 12. See Tables 4-10 for values of the other parameters. The left-hand boundary, $y=0$, corresponds to the cathode channel/gas diffusion layer interface and the right-hand boundary, $y=500 \mu \mathrm{m}$, to the anode channel/gas diffusion layer interface. The region $225 \mu \mathrm{m}<y<275 \mu \mathrm{m}$ corresponds to the membrane.

rate of water production and in the anode water is consumed in the oxidation reaction (R7). The lower current density will also reduce back diffusion caused by the drag of water molecules attached to protons, from the anode to cathode, as is seen from Eq. (6). A main consequence of the reduced saturation levels is a decrease in the membrane conductivity, which depends on the water content in the membrane according to Eq. (14). The water content in turn is a function of the local saturation and water vapour levels. Thus, the reduction in current density due to sulfur coverage of the platinum sites is compounded by a reduced membrane conductivity.

\section{Conclusions}

A modelling framework for predicting and studying the poisoning effect of $\mathrm{H}_{2} \mathrm{~S}$ on the anode catalyst layer of a PEM fuel cell has been developed. In contrast to the model in [16], the present model explicitly include mass, energy and momentum conservation, together with the fundamental modes of transport and a more detailed kinetic mechanism. The model can simulate both galvanostatic and potentiostatic operation. Comparison with data available in the open literature has shown that the trends are well captured 
with respect to variations in the $\mathrm{H}_{2} \mathrm{~S}$ concentration, cell voltage and current.

The model predicts that temperature and water activity variations have a complicated effect on the poisoning process. The kinetic mechanism in the anode is intimately linked with variations in these quantities, which also yield a wider influence on performance, through the form of the reaction rates. For example, oxidation of sulfur from the platinum surfaces in the anode consumes water, and is therefore dependent on the channel water activity. It has been demonstrated that the anode water levels can decrease quite significantly as a consequence of this reaction. The decreased water levels in the anode will reduce the membrane conductivity, further decreasing the current density. The reduced current density as a result of poisoning in turn reduces the water production rate in the cathode and restricts back diffusion of water via proton migration. The relative strengths of these effects can be investigated with the model.

Temperature increases were shown in general to lessen the degree of poisoning, although the simulation results also suggest that the behaviour of the system over a relatively short timescale (before any steady state is reached) is not straightforward to predict and certain features may be masked by the steady-state results. For these relatively short timescales the results of this study agree with those of Mohtadi et al. [1], but at steady state the comparison is inconclusive. It has been hypothesised that the discrepancies found by Mohtadi et al. could be due to the relative changes in the rates of sulfur adsorption and oxidation as the operating temperature is varied. The adsorption rate almost certainly increases as the temperature is raised, but one can predict that there is a corresponding increase in the oxidation rate, which over long times could lead to better performance at higher temperature. More data is needed to verify these claims.

In this work several assumptions have been employed in relation to the kinetic model. The missing or estimated electrochemical constants can be estimated from experiment and input to the model, improving its accuracy. Future work will focus on obtaining these parameters and validating the model over a much broader range of operating conditions.

\section{References}

[1] R. Mohtadi, W.-K. Lee, J. van Zee, Appl. Catal. B 56 (2005) 37-42.

[2] S. Jiménez, J. Soler, R. Valenzuela, L. Daza, J. Power Sources 151 (2005) 69-73.

[3] T. Springer, T. Rockward, T. Zawodzinski, S. Gottesfeld, J. Electrochem. Soc. 148 (1) (2001) A11-A23.

[4] T. Loučka, J. Electroanal. Chem. 31 (1971) 319-332.

[5] X. Cheng, Z. Shi, N. Glass, L. Zhang, J. Zhang, D. Song, Z.-S. Liu, H. Wang, J. Shen, J. Power Sources 165 (2007) 739-756.

[6] J.J. Baschuk, X. Li, Int. J. Energy Res. 25 (2001) 695-713.

[7] K. Bhatia, C.-Y. Wang, Electrochim. Acta 49 (2004) 2333-2341.

[8] T. Loučka, J. Electroanal. Chem. 36 (1972) 369-381.
[9] T. Loučka, J. Electroanal. Chem. 44 (1973) 227.

[10] A. Contractor, H. Lal, J. Electroanal. Chem. 96 (1979) 175-181.

[11] R. Jayaram, A. Contractor, H. Lal, J. Electroanal. Chem. 87 (1978) 225-237.

[12] M. Mathieu, M. Primet, Appl. Catal. 9 (1984) 361-370.

[13] R. Mohtadi, W. Lee, S. Cowan, J. van Zee, M. Murthy, Electrochem. Solid State Lett. 6 (12) (2003) A272-A274.

[14] E. Najdeker, E. Bishop, J. Electroanal. Chem. 41 (1973) 79-87.

[15] W. Shi, B. Yi, M. Houa, F. Jing, P. Ming, J. Power Sources 165 (2007) 814-818.

[16] Z. Shi, D. Song, J. Zhang, Z.-S. Liu, S. Knights, R. Vohra, N. Jia, D. Harvey, J. Electrochem. Soc. 154 (7) (2007) B609-B615.

[17] F. Uribe, T.Zawodzinski, S. Gottesfeld, The Electrochemical Society and the International Society of Electrochemistry Meeting Abstracts, San Francisco, CA, 2-7 September, 2001.

[18] Y. Wang, H. Yan, E. Wang, J. Electroanal. Chem. 497 (2001) 163-167.

[19] C.-Y. Wang, Chem. Rev. 104 (2004) 4727-4766.

[20] A. Weber, J. Newman, Chem. Rev. 104 (2004) 4679-4726.

[21] C.-Y. Wang, P. Cheng, J. Power Sources 30 (1997) 93-196.

[22] C. Ziegler, H. Yu, J. Schumacher, J. Electrochem. Soc. 152 (8)(2005) A1555-A1567.

[23] A. Shah, G. Kim, P. Sui, D. Harvey, J. Power Sources 163 (2007) 793-806.

[24] A. Shah, P. Sui, G. Kim, S. Ye, J. Power Sources 166 (2007) 1-21.

[25] W. He, J. Yi, T. Nguyen, AIChE J. 46 (10) (2000) 2053-2064.

[26] S. Mazumder, J. Cole, J. Electrochem. Soc. 150 (11) (2004) A1510-A1517.

[27] D. Natarajan, T. Nguyen, J. Electrochem. Soc. 148 (12) (2001) A1324-1335.

[28] Y. Wang, C.-Y. Wang, Electrochim. Acta 50 (2005) 1307-1315.

[29] B. Bird, W. Stewart, E. Lightfoot, Transport Phenomena, John Wiley and Sons, 2002.

[30] S. Motupally, A. Becker, J. Weidner, J. Electrochem. Soc. 147 (9) (2000) A3171-A3177.

[31] Z. Wang, C.-Y. Wang, K. Chen, J. Power Sources 94 (2001) 40-50.

[32] T.E. Springer, T.A. Zawodzinski, S. Gottesfeld, J. Electrochem. Soc. 138 (8) (1991) A2334-A2341.

[33] J. Hinatsu, M. Mizuhata, H. Takenaka, J. Electrochem. Soc. 141 (1994) A1493-A1497.

[34] S. Ge, X. Li, B. Yi, I. Hsing, J. Electrochem. Soc. 152 (6) (2005) A1149-A1157.

[35] C. Berger, Handbook of Fuel Cell Technology, Prentice-Hall, Englewood Cliffs, NJ, 1968.

[36] J. Zhang, H. Wang, D.P. Wilkinson, D. Song, J. Shen, Z. Liu, J. Power Sources 147 (2006) 58-71.

[37] A. Adamson, Physical Chemistry of Surfaces, Interscience, New York, 1967.

[38] E. Gileadi, E. Kirowa-Eisner, J. Penciner, Interfacial Electrochemistry: An Experimental Approach, Addison-Wesley Publishing Company, Reading, MA, 1975.

[39] M. Mathias, J. Roth, J. Fleming, W. Lehnert, H.G.W. Vielstich, A. Lamm, in: Handbook of Fuel Cells-Fundamentals, Technology and Applications, vol. 3, John Wiley \& Sons, Ltd., 2003 (Ch. 46).

[40] S. Lister, G. McLean, J. Power Sources 130 (2004) 61-76.

[41] M. Williams, H. Kunz, J. Fenton, J. Electrochem. Soc. 151 (10) (2004) A1617-A1627.

[42] T.V. Nguyen, W. He, W. Vielstich, A. Lamm, H. Gasteiger, in: Handbook of Fuel Cells-Fundamentals, Technology and Applications, vol. 3, John Wiley \& Sons, 2003 (Ch. 46).

[43] U. Pasaogullari, C.-Y. Wang, K. Chen, J. Electrochem. Soc. 152 (8) (2005) A1574-A1582.

[44] J.J. Baschuk, X. Li, Int. J. Energy Res. 27 (2003) 1095-1116.

[45] Z. Ogumi, Z. Takehara, S. Yoshizawa, J. Electrochem. Soc. 131 (4) (1984) A769-A772.

[46] C. Wilke, P. Chang, AIChE J. 1 (2) (1955) 264-270.

[47] S.W. Cha, Scaling effects of flow channels in fuel cells, Ph.D. thesis, Stanford University, 2003.

[48] S. Um, C.-Y. Wang, K.S. Chen, J. Electrochem. Soc. 147 (12) (2000) A4485-4493.

[49] N. Siegel, M. Ellis, D. Nelson, M. von Spakovsky, J. Power Sources 115 (2003) 81-89.

[50] C. Ziegler, A. Schmitz, M. Tranitz, E. Fontes, J. Schumacher, J. Electrochem. Soc. 151 (12) (2004) A2028-A2041.

[51] M. Lampinen, M. Fomino, J. Electrochem. Soc. 140 (12) (1993) A3537-A3546. 